\title{
Prenatal metal mixtures and child blood pressure in the Rhea mother-child cohort in Greece
}

\author{
Caitlin G. Howe ${ }^{1,2^{*}+} \mathbb{D}$, Katerina Margetaki ${ }^{2,3+}$, Marina Vafeiadi ${ }^{3}$, Theano Roumeliotaki ${ }^{3}$, Marianna Karachaliou ${ }^{3}$, \\ Manolis Kogevinas ${ }^{4,5,6}$, Rob McConnell ${ }^{2}$, Sandrah P. Eckel ${ }^{2}$, David V. Conti ${ }^{2}$, Maria Kippler ${ }^{7}$, Shohreh F. Farzan ${ }^{2+}$ and \\ Leda Chatzi ${ }^{2+}$
}

\begin{abstract}
Background: Child blood pressure (BP) is predictive of future cardiovascular risk. Prenatal exposure to metals has been associated with higher BP in childhood, but most studies have evaluated elements individually and measured $\mathrm{BP}$ at a single time point. We investigated impacts of prenatal metal mixture exposures on longitudinal changes in $\mathrm{BP}$ during childhood and elevated BP at 11 years of age.

Methods: The current study included 176 mother-child pairs from the Rhea Study in Heraklion, Greece and focused on eight elements (antimony, arsenic, cadmium, cobalt, lead, magnesium, molybdenum, selenium) measured in maternal urine samples collected during pregnancy (median gestational age at collection: 12 weeks). BP was measured at approximately 4, 6, and 11 years of age. Covariate-adjusted Bayesian Varying Coefficient Kernel Machine Regression and Bayesian Kernel Machine Regression (BKMR) were used to evaluate metal mixture impacts on baseline and longitudinal changes in BP (from ages 4 to 11) and the development of elevated BP at age 11, respectively. BKMR results were compared using static versus percentile-based cutoffs to define elevated BP.

Results: Molybdenum and lead were the mixture components most consistently associated with BP. J-shaped relationships were observed between molybdenum and both systolic and diastolic BP at age 4. Similar associations were identified for both molybdenum and lead in relation to elevated BP at age 11. For molybdenum concentrations above the inflection points $(\sim 40-80 \mu \mathrm{g} / \mathrm{L})$, positive associations with $\mathrm{BP}$ at age 4 were stronger at high levels of lead. Lead was positively associated with BP measures at age 4, but only at high levels of molybdenum. Potential interactions between molybdenum and lead were also identified for BP at age 11, but were sensitive to the cutoffs used to define elevated BP.

(Continued on next page)
\end{abstract}

\footnotetext{
* Correspondence: Caitlin.G.Howe@Dartmouth.edu

${ }^{\dagger}$ Caitlin G. Howe and Katerina Margetaki contributed equally as co-first authors and Shohreh F. Farzan and Leda Chatzi contributed equally as cosenior authors.

'Department of Epidemiology, Geisel School of Medicine at Dartmouth, Dartmouth College, 1 Medical Center Dr, Lebanon, NH 03766, USA

${ }^{2}$ Department of Preventive Medicine, University of Southern California, Los Angeles, CA, USA

Full list of author information is available at the end of the article
}

(c) The Author(s). 2021 Open Access This article is licensed under a Creative Commons Attribution 4.0 International License, which permits use, sharing, adaptation, distribution and reproduction in any medium or format, as long as you give appropriate credit to the original author(s) and the source, provide a link to the Creative Commons licence, and indicate if changes were made. The images or other third party material in this article are included in the article's Creative Commons licence, unless indicated otherwise in a credit line to the material. If material is not included in the article's Creative Commons licence and your intended use is not permitted by statutory regulation or exceeds the permitted use, you will need to obtain permission directly from the copyright holder. To view a copy of this licence, visit http://creativecommons.org/licenses/by/4.0/. The Creative Commons Public Domain Dedication waiver (http://creativecommons.org/publicdomain/zero/1.0/) applies to the data made available in this article, unless otherwise stated in a credit line to the data. 
(Continued from previous page)

Conclusions: Prenatal exposure to high levels of molybdenum and lead, particularly in combination, may contribute to higher BP at age 4. These early effects appear to persist throughout childhood, contributing to elevated BP in adolescence. Future studies are needed to identify the major sources of molybdenum and lead in this population.

Keywords: Metals, Mixtures, Blood pressure, Prenatal, Childhood

\section{Background}

Elevated blood pressure (BP) is an established risk factor for cardiovascular disease (CVD) [1]. Longitudinal studies following children into adulthood have observed that even in early life, BP is predictive of future cardiovascular risk [2]. For example, elevated BP in childhood has been associated with increased risk for hypertension and premature death from coronary heart disease, as well as intermediate outcomes, including left ventricular hypertrophy and increased carotid intima-media thickness [2-4]. Higher BP levels in childhood have also been associated with lower cognitive test scores in both early adulthood and mid-life [5]. It is therefore critical to identify modifiable factors that influence BP in early life.

There is substantial evidence supporting a link between exposure to metals, metalloids, and metalloid-like elements (hereafter collectively referred to as "metals") and risk for hypertension and CVD [6-9]. In fact, a representative study of the general population in the United States has estimated that molybdenum $(\mathrm{Mo})$, lead $(\mathrm{Pb})$, and antimony $(\mathrm{Sb})$ each contribute to $\sim 6-7 \%$ of the population attributable risk for high BP [8]. Several studies have also reported that arsenic (As) and cadmium $(\mathrm{Cd})$ exposures increase risk for elevated $\mathrm{BP}$ and hypertension in adult populations [10-12]. Essential elements, including cobalt $(\mathrm{Co})$, magnesium $(\mathrm{Mg})$, and selenium (Se), have also been associated with BP levels in adults [13-18]. However, these relationships may be complex, as these elements have critical physiological functions, but can be toxic at high levels $[19,20]$.

Although more limited, a growing body of evidence suggests that metal exposures also contribute to elevated $\mathrm{BP}$ in children and adolescents [21-25]. Exposure to toxic metals during the prenatal period may be particularly detrimental, as fetal development consists of a series of carefully-timed events, and dysregulation of these processes can have long-lasting consequences [26]. In support of this, several studies have reported positive associations between toxic metal exposures during pregnancy and BP levels in childhood [27-30]. However, most of these studies evaluated metals individually (focusing on $\mathrm{Pb}$ ) and measured BP at a single time point. Far less is known about the impacts of complex metal mixtures, which are more representative of human exposures, on longitudinal changes in BP during childhood.

In the current study, we focused on a cohort of children in Greece [31], a country with a high prevalence of pediatric hypertension [32-35]. We examined the impact of prenatal exposure to a complex mixture of metals on 1) longitudinal changes in BP across 7 years of follow-up (ages 4 to 11) and 2) risk of elevated BP at 11 years of age. We investigated eight metals ( $\mathrm{As}, \mathrm{Cd}, \mathrm{Co}, \mathrm{Mg}, \mathrm{Mo}, \mathrm{Pb}$, $\mathrm{Sb}, \mathrm{Se}$ ) that have been associated individually with $\mathrm{BP}$ in either children or adults and used flexible mixture modeling approaches that can capture complex nonlinear relationships and possible synergistic and antagonistic relationships between mixture components [36, 37], including a novel approach that can accommodate longitudinal data [37].

\section{Methods \\ Study participants}

The current study focused on a subset of mother-child pairs from the Rhea Study, a longitudinal cohort in Heraklion, Crete, Greece [31]. Briefly, participants were included in Rhea if they were pregnant, residents of the study area, 16 years of age or older, and had no communication handicap. Participants were recruited in early pregnancy at the time of their first major ultrasound examination $(<15$ weeks' gestation). The current study focused on 176 mother-child pairs with urinary metal measurements (excluding extreme outliers based on the mean \pm 4 SD), child BP measures at all three time points $(4,6$, and 11 years of age), and complete covariate information (Fig. S1). This study was conducted according to the principles of the Declaration of Helsinki and was approved by the ethical committee of the University Hospital in Heraklion, Greece and the Regional Ethical Review Board in Stockholm, Sweden. Informed consent was obtained from all participants.

\section{Urine collection and urine metals analysis}

In early pregnancy (median (IQR): 12 [11, 15] weeks' gestation), maternal spot urine samples were collected in sterile, polypropylene urine cups. These urine samples were aliquoted into $4 \mathrm{ml}$ cryotube vials (Thermo Fisher Scientific, USA) and stored at $-80{ }^{\circ} \mathrm{C}$. A panel of 15 metals was measured in urine by inductively coupled plasma mass spectrometry (Agilent 7700X; Agilent Technologies, Tokyo, Japan) with an Octopole Reaction System at the Institute of Environmental Medicine, Karolinska Institutet, Stockholm, Sweden. Urine samples were diluted 1:10 in 1\% nitric acid (prepared from 65\% 
Suprapur, Merck, Darmstadt, Germany). For the current study, we focused on a subset of eight metals [As $(\mathrm{m} / \mathrm{z}$ $75), \mathrm{Cd}(m / z 111)$, Co $(m / z 59), \operatorname{Mg}(m / z 24)$, Mo $(m / z$ 95), $\mathrm{Pb}(m / z 202), \mathrm{Sb}(m / z 121)$, Se $(m / z 75)]$ that have previously been associated individually with $\mathrm{BP}$ and for which urine is considered an acceptable biomarker of exposure $[8,11-16,21-25,27-30,38-45]$. The one exception to this second criterion was $\mathrm{Pb}$, as blood is the preferred biomarker of exposure [46]. However, we retained $\mathrm{Pb}$, because urine can capture inter-individual differences in exposure [46], and $\mathrm{Pb}$ has been associated with elevated BP in both children and adults across multiple populations $[8,27,29,30,38]$. The limits of detection (LOD) for As, Cd, Co, Mg, Mo, Pb, Sb, and Se were $<0.03 \mu \mathrm{g} / \mathrm{L},<0.001 \mu \mathrm{g} / \mathrm{L},<0.001 \mu \mathrm{g} / \mathrm{L},<1.2 \mu \mathrm{g} / \mathrm{L}$, $<0.03 \mu \mathrm{g} / \mathrm{L},<0.003 \mu \mathrm{g} / \mathrm{L},<0.002 \mu \mathrm{g} / \mathrm{L}$, and $<0.014 \mu \mathrm{g} / \mathrm{L}$, respectively. One sample had a $\mathrm{Sb}$ concentration below the LOD; the machine value for $\mathrm{Sb}$ was retained for this sample. All other samples were above the LOD for each metal. Quality control was performed by including two commercial control materials (Seronorm $^{\mathrm{TM}}$ Trace Elements Urine Blank, REF 201305, LOT OK4636 and Seronorm $^{\text {TM }}$ Trace Elements Urine, REF 201205, LOT NO2525) in each analytical run. Overall, the obtained urinary element concentrations showed good agreement with the reference value for each element (Table S1).

\section{Specific gravity}

Urinary specific gravity was measured using a digital refractometer (EUROMEX RD712 Clinical Refractometer; Euromex Microscopen BV, Arhnem, Holland). To account for urine dilution, urinary metal concentrations were adjusted for specific gravity using the following formula: urinary concentration $\times[($ mean specific gravity $(1.020)-1)$ / (individual specific gravity - 1)]) [47].

\section{Child BP measures}

Trained research assistants measured systolic BP (SBP) and diastolic BP (DBP) at approximately 4, 6, and 11 years of age. After $5 \mathrm{~min}$ of rest in a seated position, BP measures were obtained using a Dinamap automated oscillometric recorder (Dinamap Pro Care 400, Critikon, Tampa, FL) from the child's right arm with a cuff that was of appropriate size for the child's arm circumference. A minimum of three BP measurements were obtained at each visit, taken one minute apart. The average of these measurements was calculated for both SBP and DBP [48]. For primary analyses, elevated BP at 11 years of age was defined as a SBP measure $\geq 110 \mathrm{mmHg}$ and/or a DBP measure $>70 \mathrm{mmHg}$ [49]. Xi et al. have previously proposed this definition for elevated BP for children aged 6-11, because these static cutoffs are easier to implement in clinical settings [49]. This definition of elevated BP in childhood is similarly predictive of hypertension and preclinical CVD in adulthood as the American Academy of Pediatrics (AAP) definition, which uses percentile-based cutoffs $[49,50]$. In sensitivity analyses, we also examined elevated BP at age 11 defined using the AAP guidelines (i.e., SBP and/or DBP greater than or equal to the 90th percentile for sex, age, and height) [51].

\section{Covariate information}

Personal interviews combined with self-administered questionnaires and medical records were used to obtain information on potential confounders and precision variables. These included maternal age at urine collection, duration of maternal education at recruitment ( $\leq 6$ years, $>6$ years and $<12$ years, or $\geq 12$ years), maternal prepregnancy BMI $\left(\mathrm{kg} / \mathrm{m}^{2}\right)$, and maternal ever tobacco smoke use during pregnancy (reported at 12 weeks' gestation). Child characteristics included: age, sex, height, BMI, and environmental tobacco smoke (ETS) exposure in childhood at each time point $(4,6,11$ years), which was defined as any member of the household smoking more than one cigarette inside the home at the time of the interview. Child height and weight were measured by trained research assistants using a validated scale (Seca Bellisima 841 scale; Seca GmbH \& Co. KG, Hamburg, Germany) according to standard operating procedures. Child overweight and obesity were estimated using the International Obesity Task Force guidelines [52]. In preliminary models, we also evaluated the impact of additionally adjusting models for the frequency (number of times per week) of maternal fish and seafood consumption during pregnancy for the 150 participants who had this information available. Maternal fish and seafood consumption was determined using a food frequency questionnaire administered at recruitment [53]. Results were similar after this additional adjustment, so this covariate was excluded from final models.

\section{Statistical analyses}

Statistical analyses were conducted using Stata 16 and $\mathrm{R}$ (Version 3.6.2). Descriptive statistics were calculated for participant demographics, urinary metal concentrations, and BP measures. Because the urinary metals were largely right-skewed, they were $\log _{2}$-transformed to reduce the influence of extreme values. These measures were then mean-centered and scaled. Pearson correlations were used to evaluate relationships between each pair of metals. Because we hypothesized a priori that 1) essential elements (Co, Mg, Mo, Se) would have nonlinear relationships with $\mathrm{BP}, 2$ ) toxic and essential elements would act in opposing directions, and 3) some metals would act synergistically or antagonistically, we used two mixture modeling approaches that can accommodate and examine these scenarios. We used Bayesian 
Varying Coefficient Kernel Machine Regression (BVCKMR) to evaluate prenatal metal mixture impacts on DBP and SBP at age 4 (baseline) and also on longitudinal changes in these BP measures during childhood. BVCKMR is a recently developed approach that, unlike most environmental mixture methods, can accommodate longitudinal data by estimating associations between mixtures and health outcome trajectories [37]. To evaluate the impact of prenatal metal mixtures on elevated BP at 11 years of age, we used a similar mixture modeling method, Bayesian Kernel Machine Regression (BKMR) [36], which was primarily designed for evaluating outcomes measured at a single time point.

The BVCKMR model is defined as

$$
\begin{aligned}
y_{\mathrm{i} j}= & \gamma_{1}+\gamma_{2} \times \operatorname{age}_{\mathrm{i} j}+h_{1}\left(\mathrm{z}_{1 \mathrm{i}}, \cdots, \mathrm{z}_{\mathrm{Mi}}\right) \\
& +h_{2}\left(\mathrm{z}_{1 \mathrm{i}}, \ldots, \mathrm{z}_{\mathrm{Mi}}\right) \times \operatorname{age}_{\mathrm{i} j}+\mathbf{x}_{\mathbf{i}}^{\mathrm{T}} \boldsymbol{\beta}+\mathrm{u}_{\mathrm{i} j}^{\mathrm{T}} \mathrm{b}_{\mathrm{i}}+\in \mathrm{i} j
\end{aligned}
$$

where the outcome $y_{i j}$ is related to the exposure mixture $\mathrm{z}_{\mathrm{i}}=\left(\mathrm{z}_{1 \mathrm{i}}, \ldots, \mathrm{z}_{\mathrm{Mi}}\right)^{\mathrm{T}}$ through two flexible functions $\mathrm{h}_{1}(\cdot)$ and $h_{2}(\cdot)$, controlling for potential confounders $x_{i}=\left(x_{1 i}\right.$, ..., $\mathrm{x}_{\mathrm{pi}}$ ) [37]. The $h_{1}$ function represents the association between the mixture and the BP measures at baseline (age 4) while $h_{2}$ represents how the mixture modifies the annual rate of change in the BP measure over time (age 4 to 11). This BVCKMR model assesses the directionality and relative importance of each mixture component on linear health outcome trajectories, while accounting for possible nonlinear relationships between each exposure and outcome and non-additive effects of the mixture components [37]. The relative importance of each mixture component is defined as the difference in the outcome, comparing the individual metal of interest at high levels (75th percentile) versus low levels (25th percentile), while holding all other metals constant at their median values. Metal-outcome associations were considered statistically significant if the posterior credible interval for the effect estimate did not span 0. We ran 100,000 MCMC iterations, using the first half of iterations as burn-in.

The BKMR model is defined as

$$
y_{\mathrm{i}}=h\left(\mathrm{z}_{1 \mathrm{i}}, \cdots, \mathrm{z}_{\mathrm{Mi}}\right)+\mathbf{x}_{\mathrm{i}}^{\mathrm{T}} \boldsymbol{\beta}+\in \mathrm{i}
$$

where function $h()$ represents the kernel exposureresponse machine function, coefficients $\boldsymbol{\beta}^{T}$ represent effect estimates for the $X$ th covariate for the $i$ th individual, and $\varepsilon_{i}$ represents the model residuals [36]. Using the "bkmr" R package, we chose the hierarchical variable selection option, grouping elements into toxic (As, $\mathrm{Cd}$, $\mathrm{Pb}, \mathrm{Sb}$ ) and essential (Co, $\mathrm{Mg}, \mathrm{Mo}, \mathrm{Se}$ ) elements, given a priori hypotheses that metals within each group would similarly impact BP (i.e., adverse effects for toxic metals and non-linear relationships for essential elements), and ran 100,000 MCMC iterations. The first half of iterations was used as burn-in. To reduce potential autocorrelation, we thinned the chains, selecting every 10th iteration. Model convergence was visually inspected using trace plots. Posterior inclusion probabilities (PIPs) were used to rank the importance of each mixture component.

BKMR and BVCKMR models were adjusted for hypothesized confounders and precision variables, identified using directed acyclic graphs (DAGs) (Fig. S2). Final BKMR and BVCKMR models were adjusted for the minimum set of potential confounders necessary to close all backdoor paths between the exposure and outcome: maternal age (continuous), maternal education (categorical: $\leq 6$ years, $>6$ years and $<12$ years, or $\geq 12$ years), maternal pre-pregnancy BMI (continuous), and maternal smoking during pregnancy (binary: ever versus never). Models were also adjusted for three potential precision variables that were prioritized because they are known to be important predictors of BP in children [51]: child sex (binary: female versus male), child's exact age (continuous), and child height (continuous) at the relevant time points (11-year time point only for BKMR; 4-, 6-, and 11-year time points for BVCKMR). Given the high prevalence of ETS exposure among children in Greece $[54,55]$, we also examined results from both BVCKMR and BKMR models after additionally adjusting for this potential precision variable in sensitivity analyses (ETS exposure at each time point for BVCKMR and ETS exposure at age 11 for BKMR). Child BMI was identified as a potential collider based on our DAG (Fig. S2), and was therefore excluded from all models. In sensitivity analyses, we compared BKMR results when using the AAP percentile-based cutoffs [51] with the static cutoffs proposed by Xi et al. [49] to define elevated BP at age 11 .

For confirmatory analyses, we compared results from BVCKMR (for SBP and DBP measures) using generalized additive mixed models (GAMMs), in which each metal was evaluated individually. Similarly, BKMR results (for elevated BP at age 11) were compared with results from generalized additive models (GAMs). We conducted GAMMs and GAMs using the "mgcv" $\mathrm{R}$ package [56]. These models were adjusted for the same set of covariates as the BVCKMR and BKMR models, respectively. Interactions between pairs of metals were examined for both sets of models, and statistical significance was determined for the individual metal associations and pairwise interactions using a $p$-value threshold of 0.05 .

\section{Results}

Participant characteristics are shown in Table 1. The mean (SD) maternal age and pre-pregnancy BMI was 30 (4) years and $24.0(4.0) \mathrm{kg} / \mathrm{m}^{2}$, respectively, and $23 \%$ of the women reported ever smoking during the pregnancy. There were more female (55.7\%) than male (44.3\%) children in the study sample. The mean (SD) BMI at age 4, 6, and 11 was $16.4(2.0) \mathrm{kg} / \mathrm{m}^{2}, 16.8(2.7) \mathrm{kg} / \mathrm{m}^{2}$, and 20.4 
Table 1 Characteristics of 176 Mother-Child Pairs from the Rhea Cohort

\begin{tabular}{|c|c|c|c|}
\hline \multirow{2}{*}{\multicolumn{2}{|c|}{$\begin{array}{l}\text { Participant Characteristic } \\
\text { Maternal Characteristics }\end{array}$}} & \multicolumn{2}{|l|}{$\mathrm{N}(\%)$ or Mean (SD) } \\
\hline & & & \\
\hline \multicolumn{2}{|l|}{ Maternal Age, years } & \multicolumn{2}{|l|}{$30.3(4.2)$} \\
\hline \multicolumn{2}{|l|}{ Pre-Pregnancy BMI, kg/m² } & \multicolumn{2}{|l|}{$24.0(4.0)$} \\
\hline \multicolumn{4}{|l|}{ Maternal Education } \\
\hline \multicolumn{2}{|l|}{ Low ( $\leq 6$ years) } & \multicolumn{2}{|l|}{$18(10.2)$} \\
\hline \multicolumn{2}{|l|}{ Medium ( $>6$ years and < 12 years) } & \multicolumn{2}{|l|}{$90(51.1)$} \\
\hline \multicolumn{2}{|l|}{ High ( $\geq 12$ years) } & \multicolumn{2}{|l|}{$68(38.6)$} \\
\hline \multicolumn{4}{|l|}{ Smoking During Pregnancy } \\
\hline Non-Smoker & & \multicolumn{2}{|l|}{$136(77.3)$} \\
\hline Smoker & & \multicolumn{2}{|l|}{$40(22.7)$} \\
\hline $\begin{array}{l}\text { Frequency of Fish and Seafood } \\
\text { Consumption }{ }^{\mathrm{a}} \text {, Times/Week }\end{array}$ & & \multicolumn{2}{|l|}{$1.0(0.6)$} \\
\hline \multicolumn{4}{|l|}{ Child Characteristics } \\
\hline \multicolumn{4}{|l|}{ Sex } \\
\hline Male & \multicolumn{3}{|c|}{$98(55.7)$} \\
\hline Female & \multicolumn{3}{|c|}{$78(44.3)$} \\
\hline \multicolumn{4}{|c|}{ Elevated Blood Pressure at Age 11 (Static Cutoffs) $^{\text {b }}$} \\
\hline Elevated & \multicolumn{3}{|c|}{$54(30.7)$} \\
\hline Normal & \multicolumn{3}{|c|}{$122(69.3)$} \\
\hline \multicolumn{4}{|c|}{ Elevated Blood Pressure at Age 11 (Percentile Cutoffs) $^{c}$} \\
\hline Elevated & \multicolumn{3}{|c|}{$31(17.6)$} \\
\hline Normal & \multicolumn{3}{|c|}{$145(82.4)$} \\
\hline Repeated Measurements & 4 Years & 6 Years & 11 Years \\
\hline Exact Age, years & $4.2(0.2)$ & $6.5(0.3)$ & $10.9(0.3)$ \\
\hline Height, cm & $104.5(4.2)$ & $120.0(4.8)$ & $144.3(6.3)$ \\
\hline $\mathrm{BMl}, \mathrm{kg} / \mathrm{m}^{2}$ & $16.4(2.0)$ & $16.8(2.7)$ & $20.4(4.1)$ \\
\hline Overweight & $25(14.2)$ & $35(19.9)$ & $58(33.0)$ \\
\hline Obese & $10(5.7)$ & $14(8.0)$ & $20(11.4)$ \\
\hline Environmental Tobacco Smoke Exposure & $74(42.8)$ & $64(36.4)$ & $45(25.6)$ \\
\hline Systolic Blood Pressure, mmHg & $90.6(7.6)$ & $94.0(8.2)$ & $105.8(9.4)$ \\
\hline Diastolic Blood Pressure, mmHg & $53.7(5.0)$ & $53.9(6.4)$ & $61.2(6.9)$ \\
\hline
\end{tabular}

(4.1) $\mathrm{kg} / \mathrm{m}^{2}$, respectively. There was a high prevalence of overweight/obesity at each age: 35 (19.9\%) at age 4, 49 $(27.8 \%)$ at age 6 , and $78(44.3 \%)$ at age 11 . On average, $\mathrm{BP}$ measures increased during childhood. The mean (SD) SBP was 90.6 (7.6) $\mathrm{mmHg}, 94.0(8.2) \mathrm{mmHg}$, and $105.8(9.4) \mathrm{mmHg}$ at ages 4, 6, and 11, respectively. For the same ages, the mean (SD) DBP was 53.7 (5.0) $\mathrm{mmHg}, 53.9$ (6.4) $\mathrm{mmHg}$, and 61.2 (6.9) $\mathrm{mmHg}$, respectively. The prevalence of elevated BP at the 11-year time point was $30.7 \%$ when using the static cutoffs proposed by $\mathrm{Xi}$ et al. [49] and $17.6 \%$ when using the percentilebased cutoffs proposed by the AAP [51]. Overall, the study sample was similar to the larger Rhea Cohort, although participating mothers were slightly older and more educated compared with women who did not meet the inclusion criteria (Table S2). There were also some very small, although statistically significant, differences between the two groups for DBP at age 6 and for SBP at age 11 (Table S2). Urinary metal concentrations for study participants are shown with and without 
Table 2 Early Pregnancy Maternal Urinary Metal Concentrations $(n=176)$

\begin{tabular}{|c|c|c|c|c|c|c|c|}
\hline $\begin{array}{l}\text { Urinary Metal } \\
\text { Concentrations }\end{array}$ & $\begin{array}{c}\text { Geometric } \\
\text { Mean }(95 \% \mathrm{Cl})\end{array}$ & p10 & p25 & p50 & p75 & p90 & $\mathrm{n}<\mathrm{LOD}$ \\
\hline \multicolumn{8}{|l|}{ Unadjusted } \\
\hline Magnesium (mg/L) & $59.6(52.4,67.7)$ & 16.6 & 35.7 & 76.1 & 11.1 & 14.5 & 0 \\
\hline Cobalt ( $\mu \mathrm{g} / \mathrm{L})$ & $0.48(0.41,0.56)$ & 0.11 & 0.26 & 0.44 & 1.07 & 1.97 & 0 \\
\hline Selenium ( $\mu \mathrm{g} / \mathrm{L})$ & $19.4(17.3,21.6)$ & 6.0 & 13.0 & 22.8 & 33.8 & 41.8 & 0 \\
\hline Molybdenum ( $\mu \mathrm{g} / \mathrm{L})$ & $58.15(51.90,65.16)$ & 20.9 & 35.8 & 61.0 & 98.4 & 145.8 & 0 \\
\hline Arsenic ( $\mu \mathrm{g} / \mathrm{L})$ & $13.55(11.01,16.68)$ & 2.7 & 5.2 & 12.1 & 30.5 & 80.1 & 0 \\
\hline Cadmium ( $\mu \mathrm{g} / \mathrm{L})$ & $0.41(0.35,0.47)$ & 0.11 & 0.23 & 0.44 & 0.77 & 1.21 & 0 \\
\hline Antimony ( $\mu \mathrm{g} / \mathrm{L})$ & $0.05(0.04,0.05)$ & 0.02 & 0.03 & 0.05 & 0.08 & 0.11 & 1 \\
\hline Lead $(\mu \mathrm{g} / \mathrm{L})$ & $0.82(0.71,0.96)$ & 0.20 & 0.52 & 1.06 & 1.56 & 2.32 & 0 \\
\hline \multicolumn{8}{|l|}{ SG-Adjusted } \\
\hline Magnesium (mg/L) & $66.9(61.3,72.9)$ & 30.9 & 50.5 & 71.3 & 100.9 & 133.4 & 0 \\
\hline Cobalt $(\mu \mathrm{g} / \mathrm{L})$ & $0.54(0.48,0.61)$ & 0.22 & 0.28 & 0.46 & 1.01 & 1.78 & 0 \\
\hline Selenium ( $\mu \mathrm{g} / \mathrm{L})$ & $21.72(20.72,22.77)$ & 15.2 & 17.3 & 21.8 & 27.0 & 31.9 & 0 \\
\hline Molybdenum ( $\mu \mathrm{g} / \mathrm{L})$ & $65.26(61.13,69.66)$ & 38.1 & 50.5 & 64.9 & 86.7 & 114.1 & 0 \\
\hline Arsenic ( $\mu \mathrm{g} / \mathrm{L})$ & $15.21(12.50,18.49)$ & 3.9 & 5.2 & 12.2 & 34.5 & 111.0 & 0 \\
\hline Cadmium ( $\mu \mathrm{g} / \mathrm{L})$ & $0.45(0.41,0.50)$ & 0.19 & 0.30 & 0.47 & 0.69 & 1.07 & 0 \\
\hline Antimony ( $\mu \mathrm{g} / \mathrm{L})$ & $0.05(0.05,0.06)$ & 0.03 & 0.04 & 0.05 & 0.07 & 0.09 & 1 \\
\hline Lead $(\mu \mathrm{g} / \mathrm{L})$ & $0.92(0.82,1.04)$ & 0.44 & 0.69 & 1.00 & 1.48 & 2.02 & 0 \\
\hline
\end{tabular}

Abbreviations used: $L O D$ limit of detection, $p 10$ 10th percentile, $p 2525$ th percentile, $p 50$ 50th percentile, $p 75$ 75th percentile, SG specific gravity

adjustment for specific gravity in Table 2, and Pearson correlations between metal pairs are shown in Fig. 1. Most of the metals were positively correlated with each other, although correlations were generally weak to moderate, ranging from \pm 0.01 to \pm 0.45 . The strongest correlation was observed between $\mathrm{Cd}$ and $\mathrm{Pb}(r=0.45$, $p<0.01)$.

BVCKMR identified statistically significant associations between Mo and both SBP and DBP (evaluated continuously) at baseline (age 4) (Fig. 2). Setting other metals to their median, an interquartile range increase in Mo was associated with a 0.7 (95\% CI: $0.0,1.4) \mathrm{mmHg}$ higher SBP and a 1.3 (95\% CI: 0.6, 1.9) $\mathrm{mmHg}$ higher DBP at age 4 (Table S3). However, these relationships were found to be J-shaped, such that the positive associations between Mo and BP measures were driven by Mo concentrations above an inflection point of $\sim 82 \mu \mathrm{g} / \mathrm{L}$ for SBP and $\sim 52 \mu \mathrm{g} / \mathrm{L}$ for DBP (Fig. 3). In contrast, inverse associations were observed for Mo concentrations falling below this inflection point (Fig. 3). U- and J-shaped relationships were also observed between $\mathrm{Mo}$ and $\mathrm{BP}$ measures when using GAMMs (Fig. S3). In addition to these baseline associations, Mo was associated with significant longitudinal changes in DBP (Fig. 2, Table S3). BVCKMR estimated that an interquartile range increase in Mo was associated with a -0.2 (95\% CI: - 0.3, 0.0) $\mathrm{mmHg}$ lower per-year increase in DBP from ages 4 to 11 (setting other metals to their median), which was linear (Fig. 3, Table S3). Mo was not associated with significant changes in SBP over time (Fig. 3, Table S3).

Although overall associations between $\mathrm{Pb}$ and the continuous BP measures were null, both for BVCKMR and GAMMs (Fig. 2, Table S3, Fig. S3), significant pairwise interactions between $\mathrm{Pb}$ and Mo were identified by GAMMs (SBP: approximate $\mathrm{p}$ for joint smooth term < 0.01, DBP: approximate $\mathrm{p}$ for joint smooth term $<0.01$ ) (Table S4). These interactions were confirmed visually by BVCKMR (Fig. 4). Positive associations were observed between $\mathrm{Pb}$ and continuous $\mathrm{BP}$ measures at age 4 when Mo levels were set to their 75th, but not 25th, percentile (with other metals set to their median) (Fig. 4). Associations between Mo and continuous BP measures at age 4 were also modified by $\mathrm{Pb}$; for Mo concentrations above the inflection points, the positive associations between $\mathrm{Mo}$ and $\mathrm{BP}$ were stronger when $\mathrm{Pb}$ levels were set to their 75 th, compared with 25 th, percentile (setting other metals to their median) (Fig. 4).

Co was associated with significantly higher levels of both SBP and DBP (evaluated continuously) at baseline (Fig. 2). Setting other metals to their median, an interquartile range increase in Co was associated with a 1.0 (95\% CI: 0.1, 2.0) $\mathrm{mmHg}$ higher SBP and a 1.0 (95\% CI: $0.1,1.9) \mathrm{mmHg}$ higher DBP at age 4. However, these relationships were found to be non-linear, such that the positive associations were only observed for Co concentrations exceeding $\sim 0.5 \mu \mathrm{g} / \mathrm{L}$ (Fig. S4). Co was also 


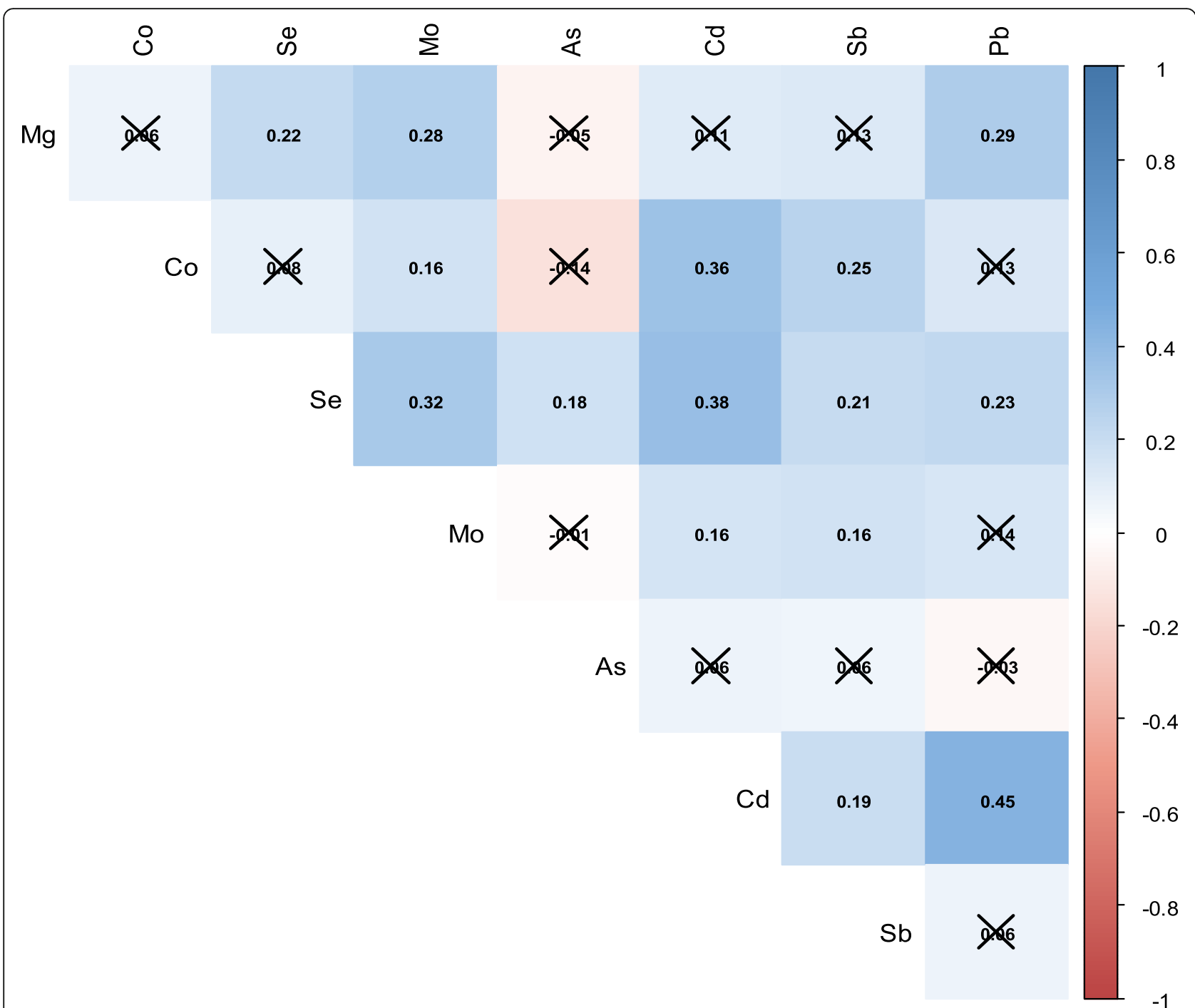

Fig. 1 Pearson Correlation Coefficients for Urinary Metal Pairs. Metals were $\log _{2}$-transformed, mean-centered, and scaled. Blue shades indicate positive correlations and red shades indicate negative correlations, as indicated in the key. X indicates that the correlation was not statistically significant ( $p$-value 20.05). Abbreviations used: As, arsenic; Cd, cadmium; Co, cobalt; Mg, magnesium; Mo, molybdenum; Pb, lead; Sb, antimony; Se, selenium

associated with significantly lower per-year increases in both SBP and DBP from ages 4 to 11 (Fig. 2, Table S3). Setting other metals to their median, BVCKMR estimated an interquartile range increase in Co to be associated with a -0.8 (95\% CI: - 1.0, - 0.5) $\mathrm{mmHg}$ lower peryear increase in SBP and a-0.4 (95\% CI: - 0.6, - 0.2) $\mathrm{mmHg}$ lower per-year increase in DBP during this period (Table S3). However, this association was nonlinear for SBP, such that the lower per-year increase in SBP was only observed for Co concentrations below $\sim 0.5 \mu \mathrm{g} / \mathrm{L}$ (Fig. S4). In contrast with the BVCKMR results, Co was not significantly associated with either SBP or DBP when evaluated individually using GAMMs (Fig. S3).

$\mathrm{Mg}$ was not significantly associated with continuous BP at baseline, but was associated with significantly higher per-year increases in both SBP and DBP from age 4 to 11 (Fig. 2, Table S3). Setting other metals to their median, BVCKMR estimated that an interquartile increase in $\mathrm{Mg}$ was associated with a 0.3 (95\% CI: 0.1, 0.4) $\mathrm{mmHg}$ higher per-year increase in SBP and a $0.4(95 \%$ CI: $0.2,0.6) \mathrm{mmHg}$ higher per-year increase in DBP. These longitudinal associations were driven by $\mathrm{Mg}$ concentrations $>66.9 \mathrm{mg} / \mathrm{L}$ (Fig. S5). $\mathrm{Mg}$ was not significantly associated with either SBP or DBP when evaluated individually using GAMMs (Fig. S3).

Although BVCKMR identified a significant inverse association between $\mathrm{Cd}$ and DBP, evaluated continuously at age 4, a similar association was not observed for SBP (Fig. 2, Table S3). Furthermore, Cd was not associated with longitudinal changes in either SBP or DBP (Fig. 2, Table S3), and GAMMs did not identify significant 
SBP 4 years (h1)

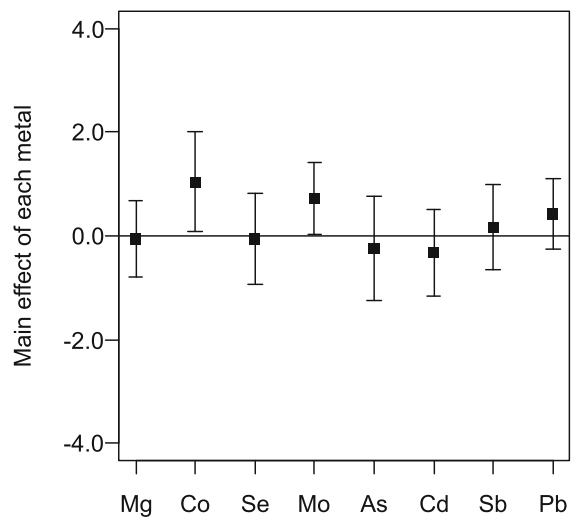

DBP 4 years (h1)

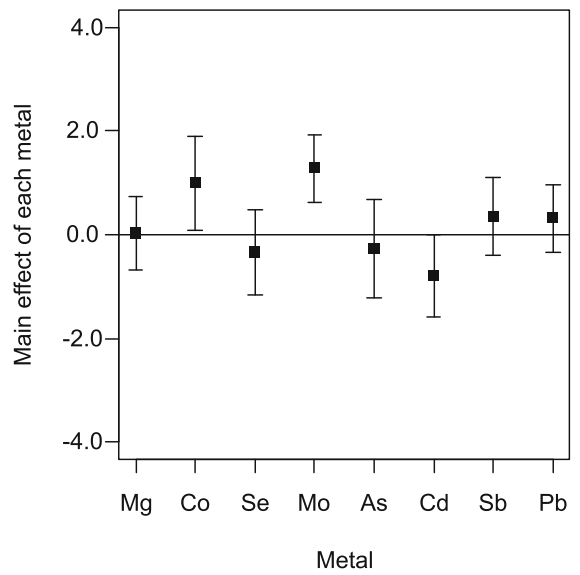

SBP yearly change (h2)

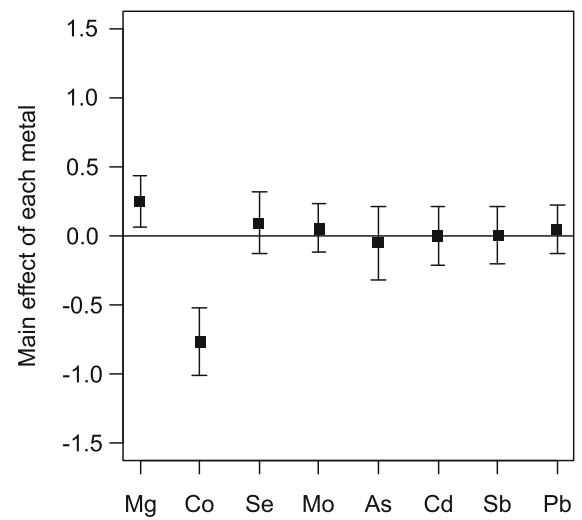

DBP yearly change (h2)

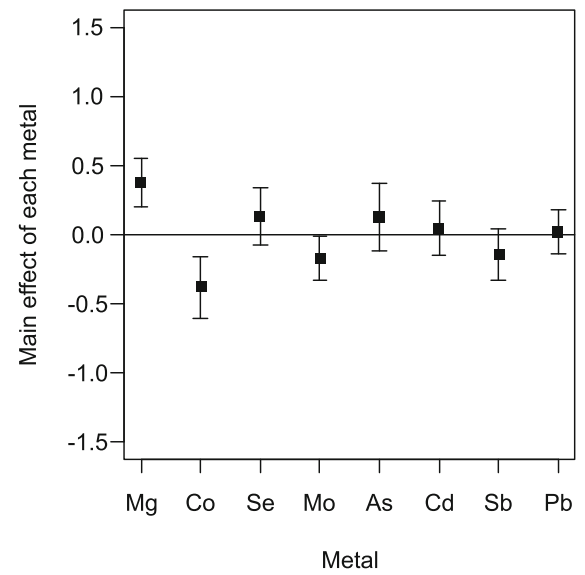

Fig. 2 BVCKMR Main Effect Estimates for Each Mixture Component. Estimates for systolic blood pressure are shown on the top row, while estimates for diastolic blood pressure are shown on the bottom row. Plots in the left column show effect estimates for baseline blood pressure measures (age 4), while plots in the right column show effect estimates for the per-year change in blood pressure from age 4 to age 11 . Effect estimates represent the difference in the outcome for an interquartile range increase in the specified metal, setting all other metals to their median value. Metals were $\log _{2}$-transformed, mean-centered, and scaled. Models were adjusted for maternal age, maternal education, maternal pre-pregnancy BMI, maternal smoking during pregnancy, child's sex, child's age, and child's height. Abbreviations used: As, arsenic; Cd, cadmium; $\mathrm{Co}$, cobalt; DBP, diastolic blood pressure; Mg, magnesium; Mo, molybdenum; Pb, lead; Sb, antimony; SBP, systolic blood pressure; Se, selenium

associations between $\mathrm{Cd}$ and either SBP or DBP (Fig. $\mathrm{S} 3)$. Associations between remaining metals (As, Sb, Se) and continuous BP measures were consistently null across methods (Fig. 2, Table S3, Fig. S3).

The primary BKMR model for elevated BP at age 11 estimated similar group PIPs for toxic and essential elements (Table S5). Within the essential element group, Mo ranked highest, and within the toxic metal group, $\mathrm{Pb}$ ranked highest (Table S5). Similar to the BVCKMR results for Mo and continuous BP at age 4, BKMR identified a J-shaped relationship between Mo and elevated BP at age 11 (Fig. 5). A J-shaped relationship was also identified between $\mathrm{Pb}$ and elevated $\mathrm{BP}$ at age 11 (Fig. 5). Additionally, a possible interaction was identified between $\mathrm{Mo}$ and $\mathrm{Pb}$ for elevated $\mathrm{BP}$ at age 11, such that the inflection point for Mo decreased with increasing levels of $\mathrm{Pb}(\sim 66 \mu \mathrm{g} / \mathrm{L}$ for $\mathrm{Pb}$ at its 10th percentile compared with $\sim 46 \mu \mathrm{g} / \mathrm{L}$ for $\mathrm{Pb}$ at its median compared with $\sim 42 \mu \mathrm{g} / \mathrm{L}$ for $\mathrm{Pb}$ at its 90 th percentile) (Fig. 5). Similarly, the inflection point for $\mathrm{Pb}$ decreased with increasing levels of Mo $(\sim 0.6 \mu \mathrm{g} / \mathrm{L}$ for Mo at its 10th percentile compared with $\sim 0.4 \mu \mathrm{g} / \mathrm{L}$ for Mo at its median compared with $\sim 0.2 \mu \mathrm{g} / \mathrm{L}$ for Mo was at its 90th percentile) (Fig. 5). Other metals were not predictive of elevated BP at age 11 (Fig. S6). Similar to the BKMR results, when evaluating the metals individually using GAMs, $\mathrm{U}$-shaped and J-shaped relationships were observed, respectively, for $\mathrm{Mo}$ and $\mathrm{Pb}$ in relation to elevated $\mathrm{BP}$ at age 11 (Fig. S7), although neither association was statistically significant (approximate $p=0.37$ and 0.49 , 
SBP 4 years (h1)

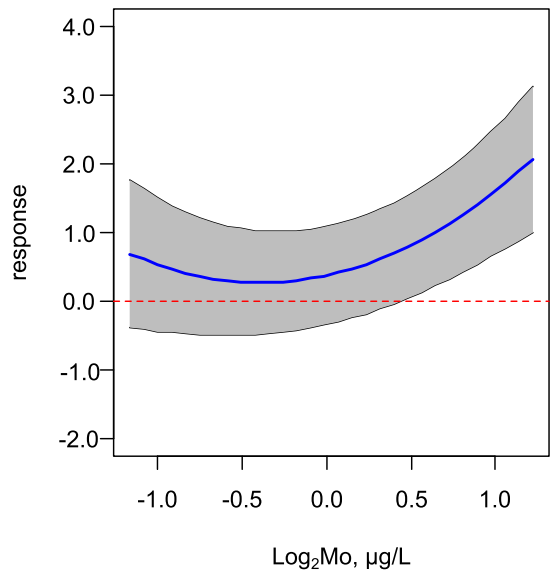

DBP 4 years (h1)

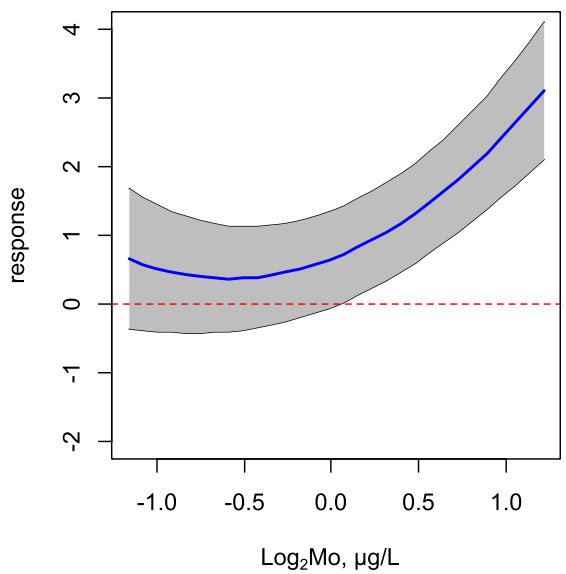

SBP yearly change (h2)

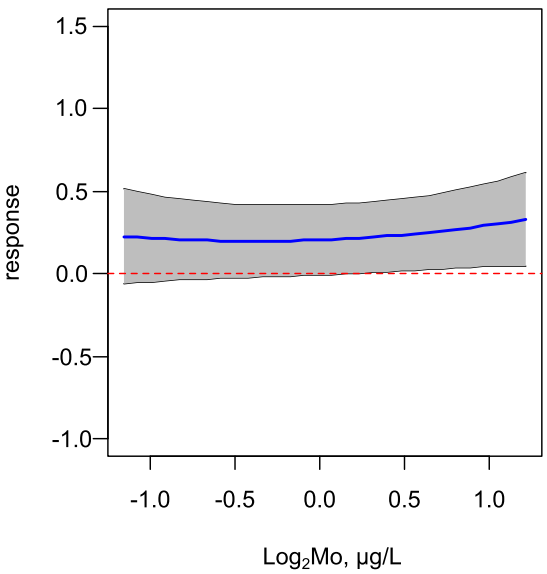

DBP yearly change (h2)

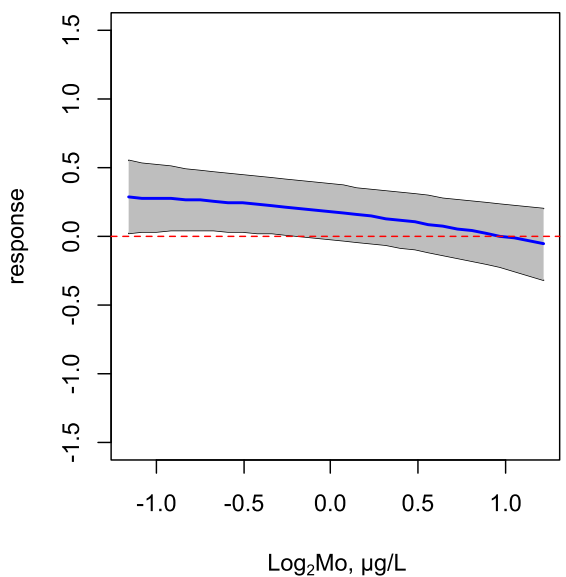

Fig. 3 BVCKMR Estimated Exposure-Response Functions for Molybdenum. Exposure-response functions for systolic blood pressure are shown on the top row, while exposure-response functions for diastolic blood pressure are shown on the bottom row. Plots in the left column show exposure-response functions for baseline blood pressure measures (age 4), while exposure-response functions for per-year changes in blood pressure measures from age 4 to 11 are shown in the right column. Molybdenum was $\log _{2}$-transformed, mean-centered, and scaled. Models were adjusted for maternal age, maternal education, maternal pre-pregnancy BMI, maternal smoking during pregnancy, child's sex, child's age, and child's height. Abbreviations used: DBP, diastolic blood pressure; Mo, molybdenum; SBP, systolic blood pressure

respectively). Furthermore, when using GAMs, inflection points of $\sim 66 \mu \mathrm{g} / \mathrm{L}$ and $\sim 0.4 \mu \mathrm{g} / \mathrm{L}$ were identified for Mo and $\mathrm{Pb}$, respectively (Fig. S7), and a suggestive interaction was identified between $\mathrm{Mo}$ and $\mathrm{Pb}$ (approximate $\mathrm{p}$ for tensor product smooth term $=0.05$ ) (Table S4).

BVCKMR results were similar after additionally adjusting for childhood ETS exposure at each time point, although the positive associations between Mo and baseline DBP and between $\mathrm{Mg}$ and the change in DBP were stronger (Table S6). The inverse association between Co and the change in DBP was also weaker after this adjustment, although still statistically significant (Table S6). BKMR results were also similar after additionally adjusting for ETS exposure at age 11 (Table S7,
Fig. S8). Mo and $\mathrm{Pb}$ consistently ranked highest for their associations with elevated BP at age 11 (Table S7). Jshaped associations were observed between each metal and this outcome, consistent with the primary model (Fig. S8). When using the AAP percentile-based cutoffs for defining elevated BP at age 11, BKMR similarly ranked $\mathrm{Mo}$ and $\mathrm{Pb}$ highest for their associations with this outcome (Table S8, Fig. S9). However, bivariate relationships between $\mathrm{Mo}$ and $\mathrm{Pb}$ were inconsistent. In contrast with the primary model, the association between Mo and elevated BP at age 11 did not differ by $\mathrm{Pb}$, and the U-shaped association between $\mathrm{Pb}$ and elevated $\mathrm{BP}$ at age 11 was only observed at low-to-moderate levels of Mo (Fig. S9). 
A $25 \% \mathrm{~Pb}, \mathrm{SBP} 4$ years (h1)

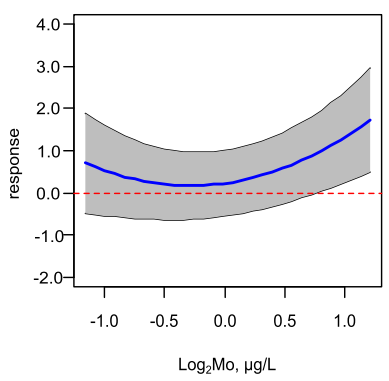

$75 \% \mathrm{~Pb}$, SBP 4 years (h1)

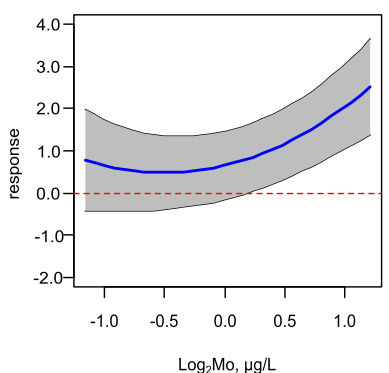

C

$25 \%$ Mo, SBP 4 years (h1)

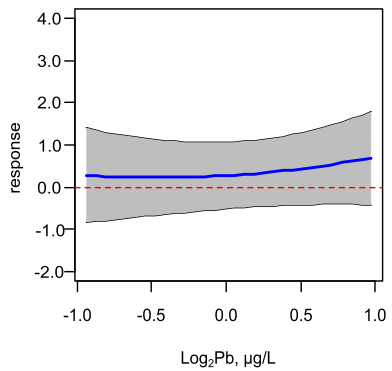

$75 \%$ Mo, SBP 4 years (h1)

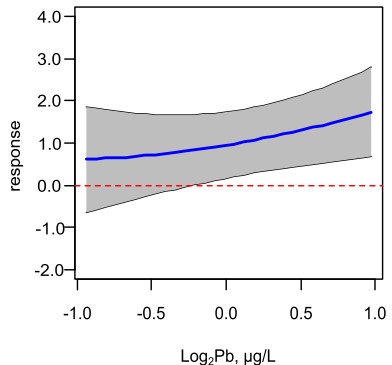

$25 \% \mathrm{~Pb}, \mathrm{SBP}$ yearly change (h2)

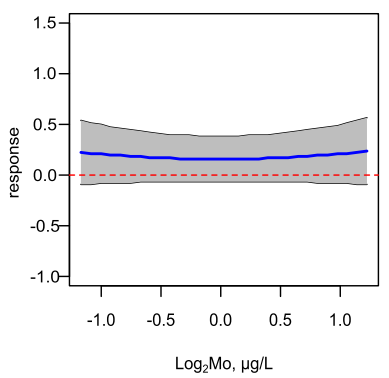

$75 \% \mathrm{~Pb}$, SBP yearly change (h2)

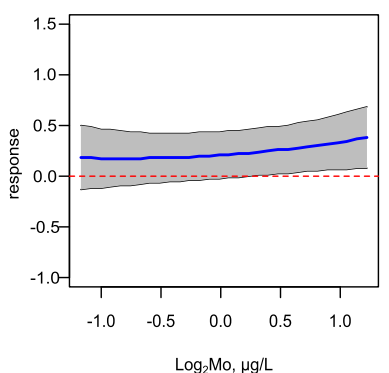

$25 \%$ Mo, SBP yearly change (h2)

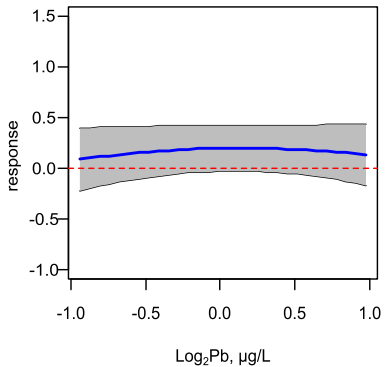

$75 \%$ Mo, SBP yearly change (h2)

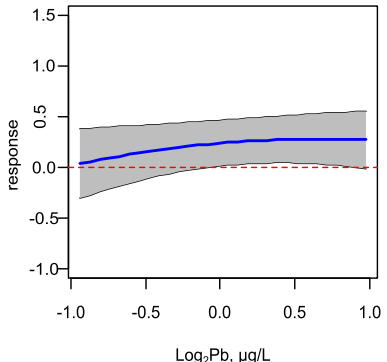

B

$25 \% \mathrm{~Pb}$, DBP 4 years (h1)

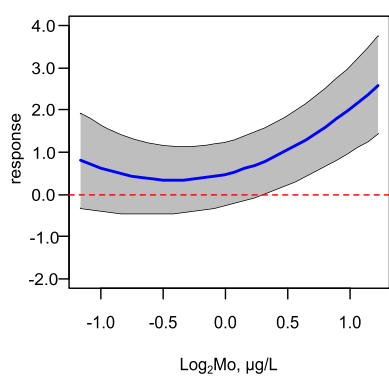

$75 \% \mathrm{~Pb}$, DBP 4 years (h1)

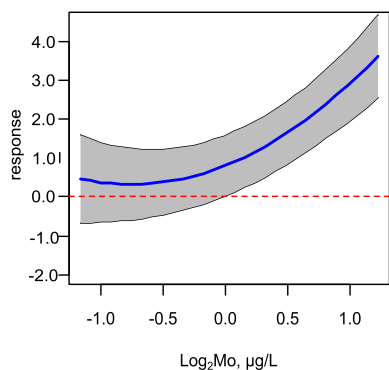

D

$25 \%$ Mo, DBP 4 years (h1)

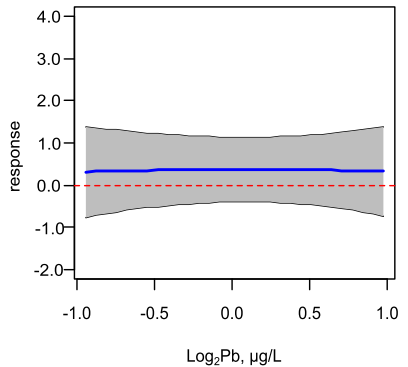

$75 \%$ Mo, DBP 4 years (h1)

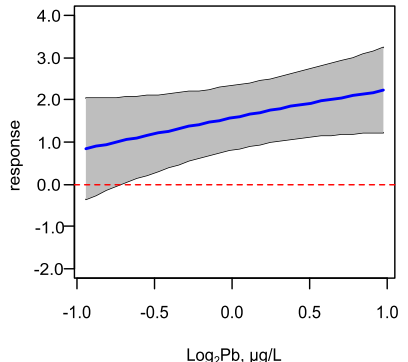

$25 \% \mathrm{~Pb}, \mathrm{DBP}$ yearly change (h2)

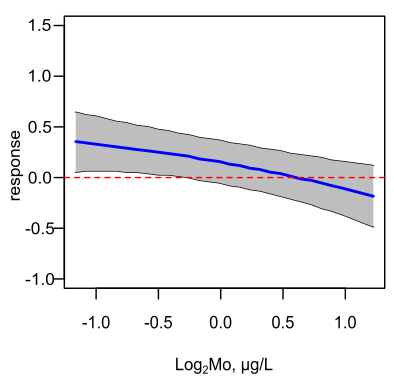

$75 \% \mathrm{~Pb}$, DBP yearly change (h2)

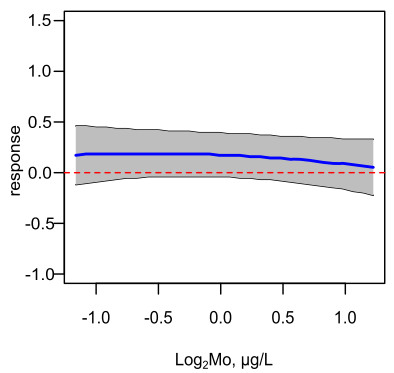

$25 \%$ Mo, DBP yearly change (h2)

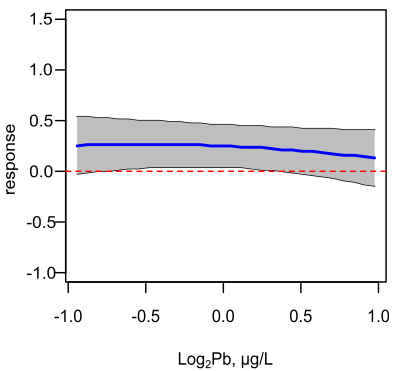

$75 \%$ Mo, DBP yearly change (h2)

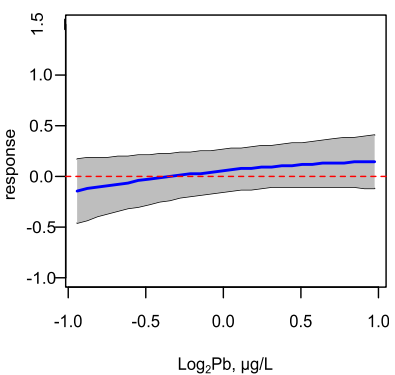

Fig. 4 BVCKMR Estimated Bivariate Exposure-Response Functions for Molybdenum and Lead. For each panel, the top row shows the exposureresponse function for metal 1 setting metal 2 to its 25th percentile, while the bottom row shows the exposure-response function for metal 1 setting metal 2 to its 75th percentile (with all other metals set to their median). The column on the left shows the exposure-response function for the baseline (age 4) blood pressure measure, while the column on the right shows the exposure-response function for the per-year change in the blood pressure measure. Panel (a) shows the molybdenum-systolic blood pressure relationship by lead level, panel (b) shows the molybdenum-diastolic blood pressure relationships by lead level, panel (c) shows the lead-systolic blood pressure relationship by molybdenum level, and panel (d) shows the leaddiastolic blood pressure relationship by molybdenum level. Molybdenum and lead were $\log _{2}$-transformed, mean-centered, and scaled. Models were adjusted for maternal age, maternal education, maternal pre-pregnancy BMl, maternal smoking during pregnancy, child's sex, child's age, and child's height. Abbreviations used: DBP, diastolic blood pressure; Mo, molybdenum; Pb, lead; SBP, systolic blood pressure 

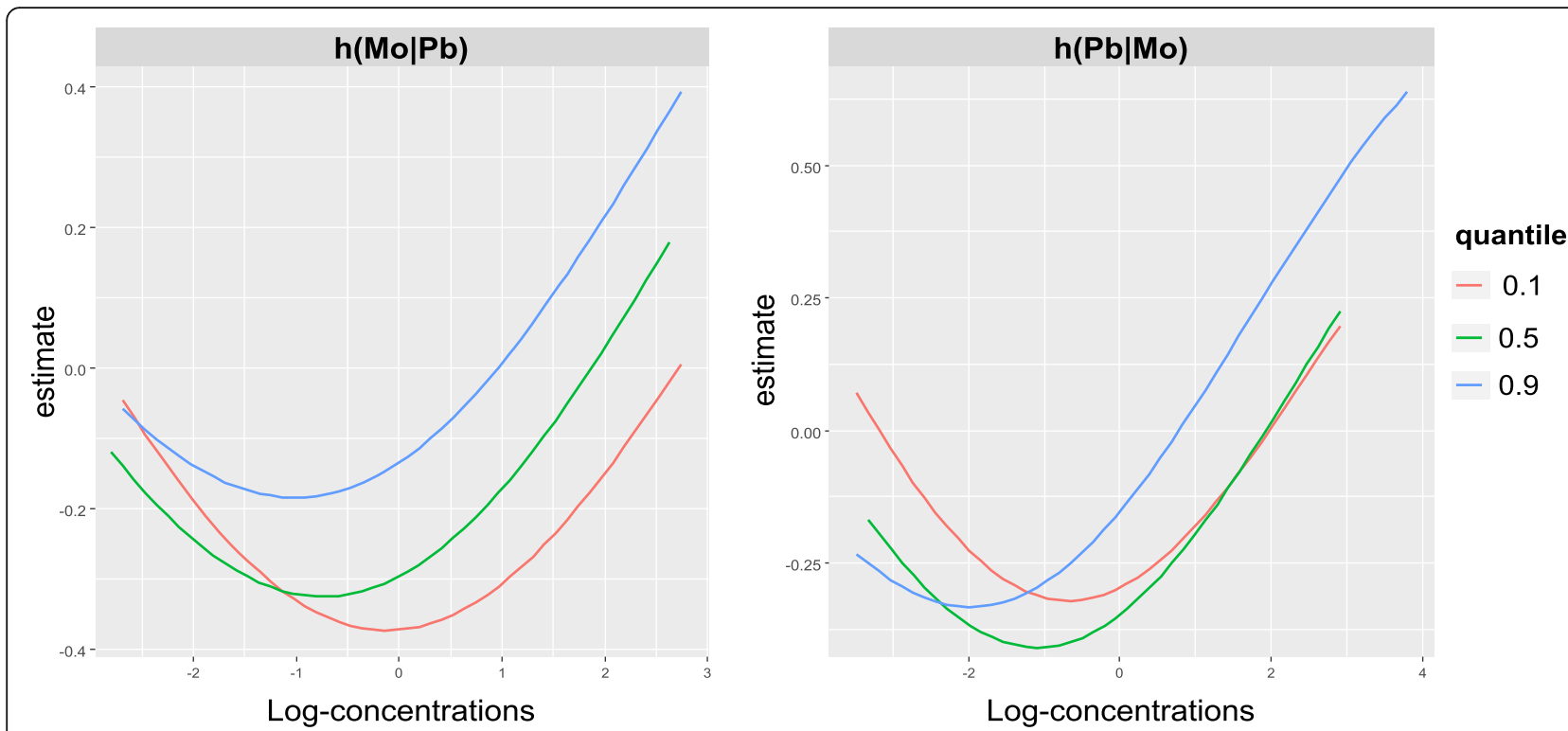

Fig. 5 BKMR Bivariate Plots for Molybdenum and Lead with Elevated Blood Pressure at Age 11. The panel on the left shows the relationship between molybdenum and elevated blood pressure at age 11 for lead set to its 10th (red), 50th (green), and 90th (blue) percentile, with all other metals in the mixture set to their median. The panel on the right shows the relationship between lead and elevated blood pressure at age 11 for molybdenum set to its 10th (red), 50th (green), and 90th (blue) percentile, with all other metals in the mixture set to their median. Molybdenum and lead were $\log _{2}$-transformed, mean-centered, and scaled. Models were adjusted for maternal age, maternal education, maternal pre-

pregnancy BMI, maternal smoking during pregnancy, child's sex, child's age, and child's height. Abbreviations used: Mo, molybdenum; Pb, lead

\section{Discussion}

In the current study, we examined the impact of prenatal metal mixture exposures on BP in a cohort of children in Greece, a country with a high prevalence of pediatric hypertension [32-34]. We used two mixture modeling approaches, including a novel method that can accommodate longitudinal data [37] and repeated BP measures spanning 7 years of follow-up to investigate the impact of prenatal exposure to a complex mixture of metals on BP trajectories in childhood and risk for elevated $\mathrm{BP}$ in early adolescence. Of the eight metals evaluated, $\mathrm{Mo}$ and $\mathrm{Pb}$ were most consistently associated with child BP. J-shaped associations were identified between each metal and continuous BP at age 4. Similar nonlinear associations were also observed for each of these metals and elevated BP at age 11. Additionally, a possible synergistic interaction between $\mathrm{Mo}$ and $\mathrm{Pb}$ was identified for BP at age 4, which was robust across multiple methods.

There is sufficient evidence supporting a link between $\mathrm{Pb}$ exposure and increased risk for hypertension in adults [57], with possible mechanisms including alterations in the transport and distribution of calcium, decreased nitric oxide availability, dysregulation of vasoactive hormones, and increased oxidative stress and inflammation [58]. However, much less is known about the effects of $\mathrm{Pb}$ exposure on BP in early life. Although several studies have reported associations between prenatal $\mathrm{Pb}$ exposure and increased $\mathrm{BP}$ in children, these studies focused on a single time point in childhood [27, $29,30]$. In the current study, we examined the impact of prenatal $\mathrm{Pb}$ exposure as part of a larger mixture on $\mathrm{BP}$ at multiple time points in childhood (4, 6 and 11 years of age). Although our longitudinal mixture analysis did not find prenatal $\mathrm{Pb}$ to be associated with significant changes in BP across childhood, it was associated with higher BP measures at age 4 and was also predictive of elevated BP at age 11. These findings suggest that prenatal $\mathrm{Pb}$ does not accelerate age-associated increases in BP during childhood, but may increase BP in early childhood, contributing to elevated BP in adolescence. Interestingly, the associations between prenatal $\mathrm{Pb}$ exposure and $\mathrm{BP}$ at age 4 varied by Mo level. Positive associations were only observed at high concentrations of Mo, indicating a potential synergistic interaction between this pair of metals. A similar interaction was also identified between $\mathrm{Pb}$ and Mo in relation to elevated $\mathrm{BP}$ at age 11 in the primary analysis, which used static cutoffs to define this outcome [49], but this interaction was not robust when using the AAP percentile-based cutoffs [51]. We therefore cannot rule out the possibility that this interaction may be a chance finding. To our knowledge, interactions between $\mathrm{Pb}$ and Mo have not previously been examined in relation to $\mathrm{BP}$.

Although less extensively studied compared with $\mathrm{Pb}$, Mo has also been associated with increased BP and related cardiovascular outcomes $[8,59,60]$. Consistent with the current study, two studies in adults have 
similarly investigated and identified non-linear relationships between Mo and BP or other cardiovascular outcomes $[59,60]$. One of these studies reported a Ushaped relationship between urinary Mo and hypertension with an inflection point $(\sim 60 \mu \mathrm{g} / \mathrm{L})$ that falls within the range of inflection points identified for Mo and BP in our study of children $(\sim 42-82 \mu \mathrm{g} / \mathrm{L})$ [59]. To our knowledge, previous studies have not investigated the longitudinal effects of Mo on BP in either children or adults. Although we found Mo to be associated with significantly smaller increases in DBP across childhood, the J-shaped relationship identified between Mo and BP at age 4 was similarly observed for elevated BP at age 11 . Thus, the effects of Mo on BP in early childhood seem to persist into adolescence despite the longitudinal decreases observed for DBP. This is likely due to SBP remaining elevated from age 4 to 11 . Interestingly, the associations between Mo and BP varied by Pb level. For example, the positive associations observed between high concentrations of Mo $(>82 \mu \mathrm{g} / \mathrm{L}$ for $\mathrm{SBP}$ and $>52 \mu \mathrm{g} / \mathrm{L}$ for $\mathrm{DBP}$ ) and continuous $\mathrm{BP}$ at age 4 were stronger at high levels of $\mathrm{Pb}$, which suggests that $\mathrm{Pb}$ may enhance the toxicity of Mo. While speculative, one potential mechanism by which $\mathrm{Mo}$ and $\mathrm{Pb}$ may jointly increase $\mathrm{BP}$ is through increased xanthine oxidase (XO) activity. $\mathrm{XO}$ is a Mo-dependent enzyme involved in purine metabolism which generates uric acid [61]. Previous studies have reported that $\mathrm{Pb}$ exposure may increase $\mathrm{XO}$ activity and uric acid levels [62-64], both of which have been associated with higher BP and increased risk for hypertension, including in children [65-69].

Although less consistent compared with findings for $\mathrm{Pb}$ and Mo, complex relationships were also identified between Co and BP, which differed by exposure level. For example, BVCKMR identified potential adverse effects of high concentrations of $\mathrm{Co}(>0.5 \mu \mathrm{g} / \mathrm{L})$ on continuous SBP and DBP at baseline, whereas low concentrations of $\mathrm{Co}(<$ $0.5 \mu \mathrm{g} / \mathrm{L}$ ) were associated with protective effects longitudinally. However, Co was not predictive of elevated BP at age 11, and no clear patterns of association were observed between Co and any of the BP measures when this metal was evaluated individually using more traditional approaches (GAMMs and GAMs). Findings from previous studies on Co and BP have also been inconsistent. For example, while serum Co has been associated with reduced risk for pregnancy-induced hypertension and lower BP levels in children [13, 22], higher urinary Co concentrations have been reported among adults with elevated BP [8]. One potential explanation for these conflicting results may be the exposure levels represented by each population, as U-shaped relationships have previously been reported between Co and other outcomes, such as fetal growth [70], indicating protective effects at low (but not high) levels of exposure [41]. However, this would not explain the inconsistencies observed in the current study when using mixture modeling versus more traditional approaches. These differences are more likely explained by confounding from metal co-exposures, which is accounted for in mixture models (BVCKMR and BKMR) but not single metal analyses (GAMMs and GAMs).

Findings for other metals were unexpected or null. For example, when using BVCKMR we observed possible adverse effects of $\mathrm{Mg}$ (at high concentrations) on child $\mathrm{BP}$ (assessed continuously). This result is inconsistent with most [15, 17, 18], though not all [71], previous studies of $\mathrm{Mg}$ and BP. For example, one study of pregnant women found urinary $\mathrm{Mg}$ excretion in early pregnancy to be associated with increased SBP in late pregnancy [71]. Importantly, most studies investigating relationships between $\mathrm{Mg}$ and BP were conducted among non-pregnant adults, and we are unaware of any studies that have examined impacts of prenatal $\mathrm{Mg}$ on child BP. Another unexpected result was the inverse association observed between urinary $\mathrm{Cd}$ and DBP at age 4 when using BVCKMR. In contrast, previous studies in adults have largely observed adverse effects of $\mathrm{Cd}$ exposure on $\mathrm{BP}$ $[10,12]$, while null associations have generally been reported for children and adolescents [38, 72-75]. However, a recent cross-sectional analysis of children and adolescents in the United States similarly observed an inverse association between urinary $\mathrm{Cd}$ and BP [72], possibly due to unmeasured confounding from diet, which is the main source of $\mathrm{Cd}$ among non-smokers [40].

Despite prior evidence that $\mathrm{As}, \mathrm{Sb}$, and Se may impact BP $[8,10-12,14-16,28,76-78]$, results for these metals were consistently null. For As and $\mathrm{Sb}$, one potential explanation may be the low exposure levels in Rhea. A null association was also observed between prenatal As exposure and child BP in the New Hampshire Birth Cohort, which is similarly represented by As exposures in the low-to-moderate range [27], and associations between $\mathrm{Sb}$ and cardiovascular outcomes have only been observed in more highly exposed adults [8, 78-81]. While numerous studies have examined relationships between Se and BP, findings have been largely inconclusive, with protective, adverse, and null associations observed depending on the study population [14]. To our knowledge, only two studies have investigated these relationships in children [77, 82]. One study, which reported higher urinary Se concentrations, observed a positive and significant correlation with DBP [77]. However, the second study, which similarly evaluated Se in the context of a mixture but measured in blood, did not find Se to be predictive of child BP [82].

Identifying sources of $\mathrm{Pb}$ and $\mathrm{Mo}$ exposure for pregnant women in Greece is critical, given the consistent adverse associations observed with BP in early childhood in Rhea. Few studies have investigated metal exposures 
in Greek populations. However, food and drinking water are major sources of $\mathrm{Pb}$ for European populations [83], and elevated $\mathrm{Pb}$ in drinking water has been observed in certain regions of Greece, including Crete [84]. Contaminated drinking water may therefore be a possible source of $\mathrm{Pb}$ exposure for this population. Diet is likely the main source of exposure for Mo [44]. Although legumes are particularly rich sources of this element, major dietary sources can vary by population. In European adults, cereals and cereal-based products are important dietary sources of Mo [85]. In the U.S., yogurt consumption has also been identified as an important predictor of urinary Mo for pregnant women, while chili pepper consumption was the strongest dietary predictor of urinary Mo in a study of pregnant women in Mexico [86, 87]. Prenatal vitamin use has also been associated with urinary Mo in certain populations, but this likely reflects concurrent use of other supplements, as prenatal vitamins do not typically contain Mo $[86,88]$. Another possible source of Mo exposure is pollution from coal combustion [44]. While coal is currently being phased out, it still contributes to a major fraction of electricity production in Greece [89].

The current study had many strengths, including the measurement and evaluation of multiple metals in early pregnancy and repeated child BP measurements across 7 years of follow up. We also used two novel mixture modeling approaches that can account for complex nonlinear associations, as well as synergistic and antagonistic relationships. To our knowledge, this is the first study to use BVCKMR, a longitudinal mixture modeling approach, to investigate the impact of an environmental mixture on child BP trajectories. By applying this method, we were able to evaluate how exposure to a complex metal mixture during pregnancy influences longitudinal changes in BP across childhood, in addition to examining impacts on BP in both early childhood and adolescence.

Our study also had important limitations. Although the estimated prevalence of elevated BP at age 11 in Rhea was similar to previous reports of elevated BP among adolescents in Greece [32-34], it may be an overestimate, as it was based on a single BP measurement [51]. However, it is unlikely that measurement error would have differed by prenatal metals exposure. While urine is an accepted biomarker of exposure for As, $\mathrm{Cd}, \mathrm{Co}, \mathrm{Mg}, \mathrm{Mo}, \mathrm{Sb}$, and $\mathrm{Se}$, it is also important to acknowledge that blood is the preferred biomarker for $\mathrm{Pb}$ [46]. While urinary $\mathrm{Pb}$ does reflect some of the interindividual differences in exposure, blood $\mathrm{Pb}$ is a more sensitive biomarker [46]. Our use of urinary $\mathrm{Pb}$ may have therefore biased results toward the null. The use of total urinary As as a biomarker of As exposure is also a limitation. While total urinary As can reflect inorganic
As and its metabolites, which are toxic, it can also reflect non-toxic arsenicals derived from fish and seafood [90]. Results were similar after additionally adjusting models for maternal fish and seafood consumption, but we cannot rule out the possibility of residual confounding. Another important consideration is that urinary metals were measured at a single time point in early pregnancy (median gestational age at collection: 12 weeks). It is therefore possible that we did not capture the most sensitive exposure window for certain elements. Our use of a single spot urine sample also has limitations, as this may reflect only very recent exposure for some metals [91]. Finally, since BVCKMR requires a minimum of three measurements per participant, the current study was restricted to a relatively small number of participants $(N=176$ for this study, compared with $N=1363$ for the full Rhea cohort). Although urinary metals did not differ between participants and non-participants, the participants in the current analysis were older and more educated on average. There were also small but statistically significant differences in some of the child BP measures. We therefore cannot rule out the possibility of selection bias. Focusing on this restricted set of participants may have also limited statistical power, particularly for the analyses investigating elevated BP at age 11. Future studies which pool data across multiple cohorts may therefore be informative.

\section{Conclusions}

Our findings suggest that high concentrations of Mo $(>40-80 \mu \mathrm{g} / \mathrm{L})$ combined with $\mathrm{Pb}$ may increase $\mathrm{BP}$ in early childhood, contributing to elevated BP in adolescence. Although we also identified possible longitudinal effects of $\mathrm{Co}$ and $\mathrm{Mg}$ (in the context of a complex mixture) on child BP, results for these metals were null when using more traditional approaches and will require additional investigation. Our findings for $\mathrm{Mo}$ and $\mathrm{Pb}$ have important public health implications, as high BP in childhood and adolescence is predictive of hypertension and CVD in adulthood [2]. Identifying major sources of Mo and $\mathrm{Pb}$ exposures in this population is therefore essential.

\section{Supplementary Information}

The online version contains supplementary material available at https://doi. org/10.1186/s12940-020-00685-9.

\section{Additional file 1.}

\section{Abbreviations}

As: Arsenic; BKMR: Bayesian Kernel Machine Regression; BP: Blood pressure; BVCKMR: Bayesian Varying Coefficient Kernel Machine Regression; Cd: Cadmium; Co: Cobalt; CVD: Cardiovascular disease; DBP: Diastolic blood pressure; ETS: Environmental tobacco smoke; GAMs: Generalized additive models; GAMMs: Generalized additive mixed models; LOD: Limit of detection; Mg: Magnesium; Mo: Molybdenum; Pb: Lead; PIP: Posterior 
inclusion probability; Sb: Antimony; SBP: Systolic blood pressure; Se: Selenium

\section{Acknowledgements}

We would like to thank the Rhea participants for their contributions to this study.

\section{Authors' contributions}

CGH and SFF conceptualized the study. CGH supervised the statistical analyses and wrote the paper. KM conducted the statistical analyses. MV, TR, and M Karachaliou were involved in study coordination. M Kogevinas founded the study cohort. SPE and DVC supervised the statistical analyses. MK supervised and coordinated the metals analyses. SFF and LC supervised the study. All authors provided feedback on the paper. The author(s) read and approved the final manuscript.

\section{Funding}

This work was supported by NIEHS [grant numbers R21ES029681 (Chatzi, Conti, McConnell), R01ES030691 (Chatzi, Conti, McConnell, Eckel), R01ES029944 (Chatzi, Conti, Margetaki), R01 ES030364 (Chatzi, Conti, McConnell, Eckel), R21ES028903 (Chatzi, McConnell, Eckel), P30ES007048 (Chatzi, Conti, McConnell, Eckel), K99 ES030400 (Howe), R00ES024144 (Farzan), and Horizon 2020 - European Framework Programme for Research and Innovation, ATHLETE, (Chatzi, Conti), P01CA196569, R01CA140561, R01ES016813 (Conti)]. The Rhea project was financially supported by the European Union [grant numbers EU FP6-2003-Food-3-NewGeneris, EU FP6. STREP Hiwate, EU FP7 ENV.2007.1.2.2.2. Project No 211250 Escape, EU FP72008-ENV-1.2.1.4 Envirogenomarkers, EU FP7-HEALTH-2009- single stage CHICOS, EU FP7 ENV.2008.1.2.1.6. Proposal No 226285 ENRIECO, EU- FP7- HEAL TH-2012 Proposal No 308333 HELIX) and the Greek Ministry of Health.

\section{Availability of data and materials}

The data that support the findings of this study may be provided by Dr. Leda Chatzi upon reasonable request.

\section{Ethics approval and consent to participate}

This study was conducted according to the principles of the Declaration of Helsinki and was approved by the ethical committee of the University Hospital in Heraklion, Greece and the Regional Ethical Review Board in Stockholm, Sweden.

\section{Consent for publication}

Informed consent was obtained from all study participants.

\section{Competing interests}

The authors declare that they have no competing interests.

\section{Author details}

'Department of Epidemiology, Geisel School of Medicine at Dartmouth, Dartmouth College, 1 Medical Center Dr, Lebanon, NH 03766, USA. 2Department of Preventive Medicine, University of Southern California, LoS Angeles, CA, USA. ${ }^{3}$ Department of Social Medicine, Faculty of Medicine, University of Crete, Heraklion, Crete, Greece. ${ }^{4}$ ISGlobal, Barcelona, Spain. ${ }^{5}$ Universitat Pompeu Fabra, Barcelona, Spain. ${ }^{6}$ CIBER Epidemiología y Salud Pública, Madrid, Spain. 'Institute of Environmental Medicine, Karolinska Institutet, Stockholm, Sweden.

Received: 7 August 2020 Accepted: 7 December 2020

Published online: 06 January 2021

\section{References}

1. Joseph P, Leong D, McKee M, Anand SS, Schwalm J-D, Teo K, et al. Reducing the global burden of cardiovascular disease, part 1: the epidemiology and risk factors. Circ Res. 2017;121(6):677-94.

2. Flynn JT. Childhood blood pressure matters. Hypertension. 2019;73(2):296-8.

3. Hao G, Wang X, Treiber FA, Harshfield G, Kapuku G, Su S. Blood pressure trajectories from childhood to young adulthood associated with cardiovascular risk: results from the 23-year longitudinal Georgia stress and heart study. Hypertension. 2017;69(3):435-42.

4. Koskinen J, Juonala M, Dwyer T, Venn A, Petkeviciene J, Ceponiene I, et al. Utility of different blood pressure measurement components in childhood to predict adult carotid intima-media thickness. Hypertension. 2019;73(2): 335-41.

5. Lande MB, Kupferman JC. Blood pressure and cognitive function in children and adolescents. Hypertension. 2019:73(3):532-40.

6. Chowdhury R, Ramond A, O'Keeffe LM, Shahzad S, Kunutsor SK, Muka T, et al. Environmental toxic metal contaminants and risk of cardiovascular disease: systematic review and meta-analysis. BMJ. 2018;362:k3310.

7. Rajagopalan S, Al-Kindi SG, Brook RD. Air pollution and cardiovascular disease: JACC state-of-the-art review. J Am Coll Cardiol. 2018;72(17):2054-70.

8. Shiue I, Hristova K. Higher urinary heavy metal, phthalate and arsenic concentrations accounted for 3-19\% of the population attributable risk for high blood pressure: US NHANES, 2009-2012. Hypertens Res. 2014; 37(12):1075-81.

9. Cosselman KE, Navas-Acien A, Kaufman JD. Environmental factors in cardiovascular disease. Nat Rev Cardiol. 2015:12(11):627-42.

10. Solenkova NV, Newman JD, Berger JS, Thurston G, Hochman JS, Lamas GA. Metal pollutants and cardiovascular disease: mechanisms and consequences of exposure. Am Heart J. 2014;168(6):812-22.

11. Abhyankar LN, Jones MR, Guallar E, Navas-Acien A. Arsenic exposure and hypertension: a systematic review. Environ Health Perspect. 2012; 120(4):494-500

12. da Cunha MA, Jr., Carneiro MFH, Grotto D, Adeyemi JA, Barbosa F, Jr. Arsenic, cadmium, and mercury-induced hypertension: mechanisms and epidemiological findings. J Toxicol Environ Health B Crit Rev. 2018;21(2):61-82

13. Liang C, Wang J, Xia X, Wang Q, Li Z, Tao R, et al. Serum cobalt status during pregnancy and the risks of pregnancy-induced hypertension syndrome: a prospective birth cohort study. J Trace Elem Med Biol. 2018:46:39-45.

14. Kuruppu D, Hendrie HC, Yang L, Gao S. Selenium levels and hypertension: a systematic review of the literature. Public Health Nutr. 2014;17(6):1342-52.

15. Kostov K, Halacheva L. Role of Magnesium Deficiency in Promoting Atherosclerosis, Endothelial Dysfunction, and Arterial Stiffening as Risk Factors for Hypertension. Int J Mol Sci. 2018;19(6):1724.

16. Wells EM, Goldman LR, Jarrett JM, Apelberg BJ, Herbstman JB, Caldwell KL, et al. Selenium and maternal blood pressure during childbirth. J Expo Sci Environ Epidemiol. 2012:22(2):191-7.

17. Joosten MM, Gansevoort RT, Mukamal KJ, Kootstra-Ros JE, Feskens EJ, Geleijnse JM, et al. Urinary magnesium excretion and risk of hypertension: the prevention of renal and vascular end-stage disease study. Hypertension. 2013;61(6):1161-7.

18. Yamori Y, Sagara M, Mizushima S, Liu L, Ikeda K, Nara Y. An inverse association between magnesium in 24-h urine and cardiovascular risk factors in middle-aged subjects in 50 CARDIAC study populations. Hypertens Res. 2015;38(3):219-25

19. Mehri A. Trace elements in human nutrition (II) - an update. Int J Prev Med. 2020;11:2.

20. Prashanth L, Kattapagari KK, Chitturi RT, Baddam VRR, Prasad LK. A review on role of essential trace elements in health and disease. J dr ntr Univ health Sci. 2015:4(2):75.

21. Sanders AP, Saland JM, Wright RO, Satlin L. Perinatal and childhood exposure to environmental chemicals and blood pressure in children: a review of literature 2007-2017. Pediatr Res. 2018;84(2):165-80.

22. Nicoloff G, Angelova M, Christova I, Nikolov A, Alexiev A. Serum cobalt in children with essential hypertension. Am J Hum Biol. 2006;18(6):798-805.

23. Spagnolo A, Morisi G, Marano G, Righetti G, Maietta A, Menotti A. Serum selenium and precursors of cardiovascular risk factors in adolescents. Eur J Epidemiol. 1991;7(6):654-7.

24. Guerrero-Romero F, Rodriguez-Moran M, Hernandez-Ronquillo G, Gomez-Diaz R, Pizano-Zarate ML, Wacher $\mathrm{NH}$, et al. Low serum magnesium levels and its association with high blood pressure in children. J Pediatr. 2016;168:93-8 e1.

25. Hirschler V, Gonzalez C, Maccallini G, Molinari C, Castano L. Association between blood pressure and magnesium and uric acid levels in indigenous Argentinean children at high altitude. Am J Hum Biol. 2017;29(4).

26. Wright RO. Environment, susceptibility windows, development, and child health. Curr Opin Pediatr. 2017:29(2):211-7.

27. Farzan SF, Howe CG, Chen Y, Gilbert-Diamond D, Cottingham KL, Jackson $\mathrm{BP}$, et al. Prenatal lead exposure and elevated blood pressure in children. Environ Int. 2018;121(Pt 2):1289-96. 
28. Hawkesworth S, Wagatsuma Y, Kippler M, Fulford AJ, Arifeen SE, Persson LA, et al. Early exposure to toxic metals has a limited effect on blood pressure or kidney function in later childhood, rural Bangladesh. Int J Epidemiol. 2013;42(1):176-85.

29. Zhang A, Hu H, Sanchez BN, Ettinger AS, Park SK, Cantonwine D, et al. Association between prenatal lead exposure and blood pressure in children. Environ Health Perspect. 2012;120(3):445-50.

30. Gump BB, Stewart P, Reihman J, Lonky E, Darvill T, Matthews KA, et al. Prenatal and early childhood blood lead levels and cardiovascular functioning in 9(1/2) year old children. Neurotoxicol Teratol. 2005;27(4):655-65.

31. Chatzi L, Leventakou V, Vafeiadi M, Koutra K, Roumeliotaki T, Chalkiadaki G, et al. Cohort profile: the mother-child cohort in Crete, Greece (Rhea study). Int J Epidemiol. 2017:46(5):1392-3k.

32. Karatzi K, Protogerou AD, Moschonis G, Tsirimiagou C, Androutsos O, Chrousos GP, et al. Prevalence of hypertension and hypertension phenotypes by age and gender among schoolchildren in Greece: the healthy growth study. Atherosclerosis. 2017;259:128-33.

33. Kollias A, Antonodimitrakis P, Grammatikos E, Chatziantonakis N, Grammatikos E, Stergiou G. Trends in high blood pressure prevalence in Greek adolescents. J Hum Hypertens. 2009;23(6):385-90.

34. Papandreou D, Stamou M, Malindretos P, Rousso I, Mavromichalis I. Prevalence of hypertension and association of dietary mineral intake with blood pressure in healthy schoolchildren from northern Greece aged 7-15 years. Ann Nutr Metab. 2007;51(5):471-6.

35. Lurbe E, Agabiti-Rosei E, Cruickshank JK, Dominiczak A, Erdine S, Hirth A, et al. 2016 European Society of Hypertension guidelines for the management of high blood pressure in children and adolescents. J Hypertens. 2016;34(10):1887-920.

36. Bobb JF, Valeri L, Claus Henn B, Christiani DC, Wright RO, Mazumdar M, et al. Bayesian kernel machine regression for estimating the health effects of multi-pollutant mixtures. Biostatistics. 2015;16(3):493-508.

37. Liu SH, Bobb JF, Claus Henn B, Gennings C, Schnaas L, Tellez-Rojo M, et al. Bayesian varying coefficient kernel machine regression to assess neurodevelopmental trajectories associated with exposure to complex mixtures. Stat Med. 2018;37(30):4680-94.

38. Skroder H, Hawkesworth S, Moore SE, Wagatsuma Y, Kippler M, Vahter M. Prenatal lead exposure and childhood blood pressure and kidney function. Environ Res. 2016;151:628-34.

39. Chou C-H, Harper C. Toxicological profile for arsenic; 2007.

40. Faroon $\mathrm{O}$, Ashizawa A, Wright $S$, Tucker $P$, Jenkins $K$, Ingerman L, et al. Toxicological profile for cadmium. 2012

41. Faroon O, Keith S. Toxicological profile for cobalt; 2004

42. Substances AT, Registry D. Toxicological profile for selenium. Atlanta, GA: ATSDR; 2003.

43. ATSDR. Toxicological Profile for Antimony and Compounds. 2019

44. Todd GD, Keith S, Faroon O, Buser M, Ingerman L, Hard C, et al. Toxicological profile for molybdenum: draft for public comment. 2017.

45. Witkowski M, Hubert J, Mazur A. Methods of assessment of magnesium status in humans: a systematic review. Magnes Res. 2012;24(4):163-80.

46. Sommar JN, Hedmer M, Lundh T, Nilsson L, Skerfving S, Bergdahl IA. Investigation of lead concentrations in whole blood, plasma and urine as biomarkers for biological monitoring of lead exposure. J Expo Sci Environ Epidemiol. 2014;24(1):51-7.

47. Nermell B, Lindberg AL, Rahman M, Berglund M, Persson LA, El Arifeen S, et al. Urinary arsenic concentration adjustment factors and malnutrition. Environ Res. 2008;106(2):212-8.

48. Gillman MW, Cook NR. Blood pressure measurement in childhood epidemiological studies. Circulation. 1995;92(4):1049-57.

49. Xi B, Zhang T, Li S, Harville E, Bazzano L, He J, et al. Can pediatric hypertension criteria be simplified? A prediction analysis of subclinical cardiovascular outcomes from the Bogalusa heart study. Hypertension. 2017;69(4):691-6.

50. Falkner B, Daniels SR. Summary of the fourth report on the diagnosis, evaluation, and treatment of high blood pressure in children and adolescents. Hypertension. 2004;44(4):387-8.

51. Flynn JT, Kaelber DC, Baker-Smith CM, Blowey D, Carroll AE, Daniels SR, et al. Clinical practice guideline for screening and management of high blood pressure in children and adolescents. Pediatrics. 2017;140(3): e20171904.

52. Cole TJ, Lobstein T. Extended international (IOTF) body mass index cut-offs for thinness, overweight and obesity. Pediatr Obes. 2012;7(4):284-94.
53. Chatzi L, Melaki V, Sarri K, Apostolaki I, Roumeliotaki T, Georgiou V, et al. Dietary patterns during pregnancy and the risk of postpartum depression: the mother-child 'Rhea' cohort in Crete, Greece. Public Health Nutr. 2011; 14(9):1663-70.

54. Vardavas Cl, Athanasopoulos D, Balomenaki E, Niaounaki D, Linardakis MK, Kafatos AG. Smoking habits of Greek preschool children's parents. BMC Public Health. 2007;7(1):112.

55. OECD, Systems EOoH, Policies. Greece: Country Health Profile 20192019.

56. Wood S, Wood MS. Package 'mgcv'. R package version, vol. 1; 2015. p. 29.

57. Navas-Acien A, Guallar E, Silbergeld EK, Rothenberg SJ. Lead exposure and cardiovascular disease--a systematic review. Environ Health Perspect. 2007; 115(3):472-82.

58. Vaziri ND. Mechanisms of lead-induced hypertension and cardiovascular disease. Am J Physiol Heart Circ Physiol. 2008;295(2):H454-65.

59. Shi $P$, Jing $H, X i S$. Urinary metal/metalloid levels in relation to hypertension among occupationally exposed workers. Chemosphere. 2019;234:640-7.

60. Xiao Y, Yuan Y, Liu Y, Yu Y, Jia N, Zhou L, et al. Circulating multiple metals and incident stroke in Chinese adults: the Dongfeng-Tongji cohort. Stroke. 2019;50(7):1661-8

61. Mendel RR, Kruse T. Cell biology of molybdenum in plants and humans. Biochimica et Biophysica Acta (BBA)-molecular. Cell Res. 2012;1823(9):1568-79.

62. Dai H, Huang Z, Deng Q, Li Y, Xiao T, Ning X, et al. The effects of Lead exposure on serum uric acid and Hyperuricemia in Chinese adults: a crosssectional study. Int J Environ Res Public Health. 2015;12(8):9672-82.

63. Krishnan $E$, Lingala B, Bhalla V. Low-level lead exposure and the prevalence of gout: an observational study. Ann Intern Med. 2012;157(4):233-41.

64. Jung W, Kim Y, Lihm H, Kang J. Associations between blood lead, cadmium, and mercury levels with hyperuricemia in the Korean general population: a retrospective analysis of population-based nationally representative data. Int J Rheum Dis. 2019;22(8):1435-44.

65. Sundstrom J, Sullivan L, D'Agostino RB, Levy D, Kannel WB, Vasan RS. Relations of serum uric acid to longitudinal blood pressure tracking and hypertension incidence. Hypertension. 2005;45(1):28-33.

66. Newaz M, Adeeb N, Muslim N, Razak T, Htut N. Uric acid, xanthine oxidase and other risk factors of hypertension in normotensive subjects. Clin Exp Hypertens. 1996;18(8):1035-50.

67. Alper AB Jr, Chen W, Yau L, Srinivasan SR, Berenson GS, Hamm LL. Childhood uric acid predicts adult blood pressure: the Bogalusa heart study. Hypertension. 2005;45(1):34-8.

68. Scheepers LE, Boonen A, Pijnenburg W, Bierau J, Staessen JA, Stehouwer $C D$, et al. Associations of plasma uric acid and purine metabolites with blood pressure in children: the KOALA birth cohort study. J Hypertens. 2017; 35(5):982-93.

69. Loeffler LF, Navas-Acien A, Brady TM, Miller ER III, Fadrowski JJ. Uric acid level and elevated blood pressure in US adolescents: National Health and nutrition examination survey, 1999-2006. Hypertension. 2012;59(4):811-7.

70. Mikelson CK, Troisi J, LaLonde A, Symes SJK, Thurston SW, DiRe LM, et al. Placental concentrations of essential, toxic, and understudied metals and relationships with birth outcomes in Chattanooga, TN. Environ Res. 2019; 168:118-29

71. Nielsen TF, Rylander R. Urinary calcium and magnesium excretion relates to increase in blood pressure during pregnancy. Arch Gynecol Obstet. 2011; 283(3):443-7.

72. Yao B, Lu X, Xu L, Wang Y, Qu H, Zhou H. Relationship between low-level lead, cadmium and mercury exposures and blood pressure in children and adolescents aged 8-17 years: an exposure-response analysis of NHANES 2007-2016. Sci Total Environ. 2020;726:138446.

73. Sanders AP, Mazzella MJ, Malin AJ, Hair G, Busgang SA, Saland JM, et al. Combined exposure to lead, cadmium, mercury, and arsenic and kidney health in adolescents age 12-19 in NHANES 2009-2014. Environ Int. 2019; 131:104993.

74. Cao Y, Chen A, Radcliffe J, Dietrich KN, Jones RL, Caldwell K, et al. Postnatal cadmium exposure, neurodevelopment, and blood pressure in children at 2, 5, and 7 years of age. Environ Health Perspect. 2009;117(10):1580-6.

75. Swaddiwudhipong W, Mahasakpan P, Jeekeeree W, Funkhiew T, Sanjum R, Apiwatpaiboon T, et al. Renal and blood pressure effects from environmental cadmium exposure in Thai children. Environ Res. 2015;136:82-7.

76. Osorio-Yáñez C, Ayllon-Vergara JC, Arreola-Mendoza L, Aguilar-Madrid G Hernández-Castellanos E, Sánchez-Peña LC, et al. Blood pressure, left ventricular geometry, and systolic function in children exposed to inorganic arsenic. Environ Health Perspect. 2015;123(6):629-35. 
77. Błażewicz A, Klatka M, Astel A, Korona-Glowniak I, Dolliver W, Szwerc W, et al. Serum and urinary selenium levels in obese children: a cross-sectional study. J Trace Elem Med Biol. 2015;29:116-22.

78. Navas-Acien A, Silbergeld EK, Sharrett R, Calderon-Aranda E, Selvin E, Guallar E. Metals in urine and peripheral arterial disease. Environ Health Perspect. 2005;113(2):164-9.

79. Agarwal S, Zaman T, Tuzcu EM, Kapadia SR. Heavy metals and cardiovascular disease: results from the National Health and nutrition examination survey (NHANES) 1999-2006. Angiology. 2011;62(5):422-9.

80. Guo J, Su L, Zhao X, Xu Z, Chen G. Relationships between urinary antimony levels and both mortalities and prevalence of cancers and heart diseases in general US population, NHANES 1999-2010. Sci Total Environ. 2016;571:452-60.

81. Mendy A, Gasana J, Vieira ER. Urinary heavy metals and associated medical conditions in the US adult population. Int J Environ Health Res. 2012;22(2): 105-18.

82. Kupsco A, Kioumourtzoglou M-A, Just AC, Amarasiriwardena C, EstradaGutierrez G, Cantoral A, et al. Prenatal metal concentrations and childhood cardiometabolic risk using Bayesian kernel machine regression to assess mixture and interaction effects. Epidemiology. 2019;30(2):263-73.

83. Alexander J, Benford D, Boobis A, Ceccatelli S, Cravedi J-P, Di Domenico A, et al. Scientific opinion on lead in food EFSA panel on contaminants in the food chain (CONTAM). EFSA J. 2010;8(4):1570.

84. Karavoltsos S, Sakellari A, Mihopoulos N, Dassenakis M, Scoullos MJ. Evaluation of the quality of drinking water in regions of Greece. Desalination. 2008;224(1-3):317-29.

85. EFSA Panel on Dietetic Products N, Allergies. Scientific Opinion on Dietary Reference Values for molybdenum. EFSA J. 2013;11 (8):3333.

86. Osorio-Yáñez C, Gelaye B, Enquobahrie DA, Qiu C, Williams MA. Dietary intake and urinary metals among pregnant women in the Pacific northwest. Environ Pollut. 2018;236:680-8.

87. Barrios PL, Vázquez-Salas RA, López-Carrillo L, Menezes-Filho JA, TorresSánchez L. Dietary determinants of urinary molybdenum levels in Mexican women: a pilot study. Salud Pública Méx. 2017;59:548-55.

88. Ashrap P, Watkins DJ, Mukherjee B, Boss J, Richards MJ, Rosario Z, et al. Predictors of urinary and blood metal (loid) concentrations among pregnant women in northern Puerto Rico. Environ Res. 2020:183:109178.

89. Nikas A, Neofytou H, Karamaneas A, Koasidis K, Psarras J. Sustainable and socially just transition to a post-lignite era in Greece: a multi-level perspective. Energy Sources B Econ Plann Policy. 2020:1-3.

90. Tseng $\mathrm{C}-\mathrm{H}$. A review on environmental factors regulating arsenic methylation in humans. Toxicol Appl Pharmacol. 2009;235(3):338-50

91. Wang $Y-X$, Feng $W$, Zeng $Q$, Sun $Y$, Wang $P$, You L, et al. Variability of metal levels in spot, first morning, and 24-hour urine samples over a 3-month period in healthy adult Chinese men. Environ Health Perspect. 2016;124(4): $468-76$

\section{Publisher's Note}

Springer Nature remains neutral with regard to jurisdictional claims in published maps and institutional affiliations.

Ready to submit your research? Choose BMC and benefit from:

- fast, convenient online submission

- thorough peer review by experienced researchers in your field

- rapid publication on acceptance

- support for research data, including large and complex data types

- gold Open Access which fosters wider collaboration and increased citations

- maximum visibility for your research: over $100 \mathrm{M}$ website views per year

At $\mathrm{BMC}$, research is always in progress.

Learn more biomedcentral.com/submissions 